Fl. Medit. 27: 5-76

doi: 10.7320/FlMedit27.005

Version of Record published online on 19 April 2017

\title{
Sustainable restoration of Mediterranean forests
}

\author{
edited by D. Chiatante, G. Domina, A. Montagnoli \& F. M. Raimondo
}

\begin{abstract}
Chiatante, D., Domina, G., Montagnoli, A. \& Raimondo, F. M. (eds): Sustainable restoration of Mediterranean forests — Fl. Medit. 27: 5-76. 2017. — ISSN: 1120-4052 printed, 2240-4538 online.

This contribution includes the 62 oral and 24 poster presentations of the international congress "Sustainable restoration of Mediterranean forests, analysis and perspective within the context of bio-based economy development under global changes", Palermo 19th - 21th April 2017, organized by the International Union of Forest Research Organizations (IUFRO), the University of Insubria, the Tuscia University, the University of Palermo, the Italian Society of forest restoration (SIRF), the Botanical Society of Italy (SBI) and the Italian Academy of Forest Sciences. The congress program is organized in four main technical Symposia: Forest restoration in Mediterranean climates (Europe/other continents); Scientific and technological advancements for a sustainable forest management; Political, social, and economical implications related to forest restoration activities; Forest restoration, landscape management, and ecosystem services. The four key themes of the symposia will be developed by answering the following questions: How climate change and its extreme events is affecting the Mediterranean vegetation in general and forests in particular; how new technological advancements will impact upon and will support the strategies to be implemented for leading to a sustainable forest management in Mediterranean Region; how to interconnect stakeholders, economists, policy makers with forest and landscape scientists in order to form a network able to guarantee a full integration of national forest infrastructures within the context of worldwide strategies for a circular economy; how the introduction of an Adaptive Measure (AM) approach could combine Adaptive Forest Management (AGM) with Forest Landscape Restoration (FLR).
\end{abstract}

Addresses of the editors:

Donato Chiatante \& Antonio Montagnoli, University of Insubria, Department of Biotechnology and Life Sciences, Via Dunant 3, 21100 Varese, Italy. E-mail: donato.chiatante@uninsubria.it, antonio.montagnoli@uninsubria.it

Gianniantonio Domina, Department SAF, University of Palermo, via Archirafi 38, I-90123 Palermo, Italy. E-mail: gianniantonio.domina@unipa.it

Francesco M. Raimondo, Department STEBICEF/Section of Botany and Plant Ecology, University of Palermo, via Archirafi 38, I-90123 Palermo, Italy. E-mail: francesco.raimondo@unipa.it 


\title{
Oral presentations
}

\section{Forest adaptation and restoration under Global Change - concept and status of an IUFRO Task Force}

\author{
Andreas Bolte ${ }^{1 *}$, Palle Madsen ${ }^{2}$, Mercy Afua Adutwumwaa Derkyi ${ }^{3} \&$ John A. Stanturf $^{4}$ \\ ${ }^{1}$ Thünen Institute of Forest Ecosystems, Alfred-Möller-Straße 1, 16225 Eberswalde, Germany. \\ ${ }^{2}$ University of Copenhagen, Forest and Lancscape College, Nødebovej 77A, 3480 Fredensborg, \\ Denmark. \\ ${ }^{3}$ University of Energy and Natural Resources, Dept. of Forest Science, School of Natural Resources, \\ P.O. Box 214, Sunyani, Ghana. \\ ${ }^{4}$ U.S. Forest Service, Southern Research Station, 320 Green Street, Athens, GA 30602-2044, United \\ States of America. \\ * Corresponding author: andreas.bolte@thuenen.de; Phone: +49 33343820344
}

Keywords: Adaptive Forest Management (AFM), Forest Landscape Restoration (FLR), best practice approach, capacity building, online survey.

Rising world population and increasing demands on forest ecosystems goods and services as well as on meat and dairy products are cascading into forest degradation or even deforestation. At the same time, forest ecosystems are facing fundamental disruptions by e.g. extreme weather events and accompanying biotic threats. Due to these changing conditions, we need more information on the adaptive capacities of trees and forests as well as on the options and limitations of Adaptive Forest Management (AFM) from the stand-scale embedded within Forest Landscape Restoration (FLR) activities to the landscape-scale. The IUFRO Task Force Forest Adaptation and Restoration under Global Change is dedicated to compiling globally-available scientific and technical knowledge and experiences on an adaptation of forests and forest landscapes. The TF conceptual pathway has three aims: identifying knowledge gaps, comparing existing activities and techniques, and elaborating best practice approaches. This shall be done by (1) considering all actions that increase adaptive capacity of forests and forest land, (2) combining Adaptive Forest Management (AFM) concepts on a stand-scale with Forest Landscape Restoration (FLR) concepts at the landscapescale, (3) linking national and trans-national policies, as well as trans-disciplinary expertise in various fields, and (4) integrating experts and working activities among various IUFRO units. Critical challenges are the limits on worldwide transfer of information about forest adaptation and restoration, as well as the need for capacity building in developing countries. Thus, TF activities are recently focusing on regional training workshops with local practitioners and the establishment of a database including worldwide knowledge and experience about successes and failures of forest adaptation and restoration activities. Data are gathered using a multilingual online survey and will be used for disseminating local and regional best practice approaches for forest adaptation and restoration. 


\section{Successful experiences of restoration of Mediterranean forests in Chile, South America}

Veronica Loewe*, Gerardo Vadevenito, Manuel Acevedo, Marta Gonzalez, Susanna Benedetti, Eduardo Cartes \& Ivan Quiroz

NFOR, Sucre 2397, Santiago, Chile.

* Corresponding author: vloewe@infor.cl; Phone: +56996896499

Keywords: dune, plant production, rainwater harvest.

Restoration of highly degraded Mediterranean ecosystems involves the assessment of both nursery propagation mechanisms of the main tree and shrub species that compose those ecosystems and the silviculture that ensure restoration success in the field. The following experiments are presented: -Rainwater harvesting techniques in areas with rainfall below $250 \mathrm{~mm}$. Oasification techniques (infiltration trenches, limans, terraces, diversion channels) had a positive effect. - Techniques for restoring the sclerophyll forest on the Andes (1500 ma.s.l.) using materials available in the area or waste materials (old car tires) were designed, promoting survival increase and growth promotion. -Peumus boldus forest, endemic species exhibiting wide plasticity and geographical distribution; leaves are used for medicinal purposes, traditionally harvested from natural forests degraded due to non-sustainable extraction practices. The response to management under different harvest intensities was evaluated, identifying those that favor resprout emergence and a better recovery. -Nothofagus alessandrii forest, endemic species endangered. Nursery plant production was studied, evaluating containers size and fertilization, and field establishment with and without individual protection. -Mixed forest of Nothofagus obliqua, Aextoxicon unctatum and Laurelia sempervirens affected by a fire. The effect of establishment with contrasting levels of artificial protection on survival and growth was evaluated for 2 years. Results show the importance of protective elements during establishment to favor initial development and increase survival. Stabilization of coastal sand dunes with Pinus pinea, characterized by its capacity to adapt to nutrient and water deficit conditions and to dunes. Experiments conducted in Chile and Argentina are presented. Even though the techniques used were different, the results were excellent, with localities having being safeguarded from the advance of sand dunes.

\section{Forest degradation, conservation and restoration in the Mediterranean Basin}

Roberto Mercurio

SIRF, Via S. Camillo de Lellis, Viterbo, Italy. E-mail: rmercurio@inwind.it

Keywords: degradation, forest restoration, human and spiritual growth.

The degradation of Mediterranean forests for overgrazing and overutilization has characterized the past centuries. In the 20th century started an important reforestation plan of 
bare lands mainly with conifers ending in the same century and representing a primeval form of forest restoration.

Following the Conference on the Human Environment of Stockholm at the beginning of the ' $70 \mathrm{~s}$ and the development of the green movement in the western Countries, the resulting strategies were based on the creation of many protected areas and developing conservative idea of passive forest management, underestimating the role of restoration of many degraded forests unable to furnish eco-services.

The restoration of degraded forest systems represents the challenge of the 21th century. The peculiarity of forest restoration in Mediterranean Basin begins counteracting the current causes of degradation such as forest fires, land abandonment, heedless urbanization, wars and criminal acts, adapting criteria and techniques to a high densely populated and altered territory by millenary human activity.

Forest restoration should be focused on improving ecological functionality and human well-being e.g. preventing floods and desertification, and enhancing carbon dioxide absorption.

Restoration is not a simple technique, it needs a public consensus and a human moral and spiritual growth.

\title{
Increasing diversity and resilience of Aleppo pine stands: thinning and introducing hardwood species
}

\author{
Bernard Prévosto $^{1 *}$, Jordane Gavinet ${ }^{2} \&$ Catherine Fernandez $^{2}$ \\ ${ }^{1}$ Irstea, route de Cézanne CS 4006113182 Aix-en-Provence cedex 5, France. \\ ${ }^{2}$ Aix-Marseille University (IMBE), Campus St Charles Case 43 place Victor Hugo 13331 Marseille \\ cedex 3, France. \\ * Corresponding author: bernard.prevosto@irstea.fr; Phone: +33 (0)4 42669925
}

Keywords: plant-plant interactions, thinning, soil moisture, light.

In Mediterranean forests, silvicultural methods to increase the resilience of the existing stands are needed to face climate change challenges. Promoting mixed stands, in particular mixed pine-hardwood stands, is of interest as it combines the rapid growth of pine and the resprouting capacity of the hardwood species.

To implement this strategy in southern France, we have introduced 2800 seedlings of six hardwood species in monospecific Aleppo pine stands and in the open. The species used were two shrubs, two deciduous trees, two common late-successional oak trees and an exotic tree. Species were planted or sown (oaks) in stands previously thinned to produce three cover treatments: low (heavy thinning), medium (medium thinning) and dense (no thinning). Seedlings were monitored during 6 years and some physiological traits were measured. Besides, light availability and microclimatic factors were also recorded.

Results showed that seedling responses to the treatments were species-specific but seedling development was always the lowest in the dense cover treatment. Survival of 
the deciduous trees was only slightly modified under medium to low pine cover compare to the open whereas height growth was largely stimulated. This result can be explained by a higher photochemical stress of these species in full light conditions whereas soil moisture remained higher in the open than in forest stands. In contrast, survival and development of the two shrub species and of the evergreen oak were improved in the open. Last, establishment of the exotic tree was largely compromised by frost damages.

Introduction of hardwood species in pine stands is a promising technic to improve forest resilience. Low to medium pine cover is favourable to deciduous trees but not to shrubs which are better adapted to open conditions. In fact, deciduous trees exhibit a shade-tolerance whereas they are subjected to photoinhibition under full light. Dense stands are particularly unfavourable to seedling establishment due to light limitation and need to be thinned.

\section{Sustainable forest restoration of degraded relict forests in Sicily}

Gianniantonio Domina ${ }^{1 *}$, Francesco Maria Raimondo ${ }^{2}$ \& Sebastiano Ciccarello ${ }^{2}$

${ }^{1}$ Department SAF, University of Palermo, via Archirafi 38, Palermo, Italy.

${ }^{2}$ Department STEBICEF, University of Palermo, via Archirafi 38, Palermo, Italy.

* Corresponding author: gianniantonio.domina@unipa.it; Phone: +39 3477027156

Keywords: colchic-atlantic vegetation, Madonie Mts., Nebrodi Mts.

In the Mediterranean region the Miocenic and Pliocenic vegetation was almost entirely destroyed or heavily disturbed by the geo-climatic events of the Quaternary. The glacial phenomenon of the Pleistocene determined the nearly complete disappearance of the subtropical aspects of lauriphyllous forests. Impoverished evergreen forests residual from the colchicatlantic vegetation still survive today on the oldest mountain ranges of the Mediterranean and testimony this humid subtropical climate vegetation. Examples are widespread above all in the Caucasus (Colchide) and in the Macaronesian areas, remains of a unique zone crossing the Mediterranean from East to West. Scattered remains occurs inside deciduous broadleaf formations in Mediterranean mountains. In some cases these are extra-zonal vegetation belts with remarkable phyto-geographic and landscaping interest as in Sicily on the Nebrodi and on the Madonie mountains. These formations, included in the class Querco-Fagetea, are characterized respectively by Quercus cerris in the Nebrodi (Ilici-Quercetum cerridis) and Q. petraea subsp. austrothirrenica in the Madonie (Ilici-Quercetum austrothyrrenicae) and share species as Ilex aquifolium, Daphne laureola, Ruscus aculeatus, Hedera helix and Evonimus europaeus. Often highly degraded aspects occur due to the overexploitation and grazing persisted from the XIX Century to years following the second World War. More than thirty-five years, after the institution of the Regional Natural parks of the Madonie and Nebrodi, some areas of natural expansion of these woods occur. Anyway, the human intervention to restore the natural floristic richness and to make possible this process in heavily degraded areas is necessary. The most suggested actions are those on small areas with plantlets coming from seeds collected on site. 


\title{
Bryophytes as ecological indicators in beech woods of Sicily
}

\author{
Marta Puglisi ${ }^{1 *}$, Patrizia Campisi ${ }^{2}$, Maria Privitera ${ }^{1}$, Maria Giovanna $\operatorname{Dia}^{2} \&$ Giovanni Spampinato ${ }^{3}$ \\ ${ }^{1}$ Department of Biological, Geological and Environmental Sciences, University of Catania, Via A. \\ Longo 19, Catania, Italy. \\ ${ }^{2}$ Department STEBICEF, University of Palermo, Via Archirafi, 38, Palermo, Italy. \\ ${ }^{3}$ Department of Agricultural Science, Mediterranean University of Reggio Calabria, Località Feo di \\ Vito, Reggio Calabria, Italy. \\ * Corresponding author: mpuglisi@unict.it
}

Keywords: bryophytes, beech woods, bioindicators, Sicily.

Beech woods, which have in Sicily one of the southernmost places of their distribution area, are localized in the mountain belt of North and North-Eastern Sicily, at an altitude of 1300-1900 m, reaching $900 \mathrm{~m}$ on the Peloritani. They are referred to the priority habitat 9210*, according to the Natura 2000 network of the European Union. Beech woods settle on different soils, such as incoherent sandy volcanic (Etna), calcareous or silico-arenaceous (Madonie) and clayey-schistose soils (Nebrodi and Peloritani). Bryophytes are considered important components of forestry ecosystems. Many of these organisms are specific to particular types of microhabitats and sensitive to changes such that species richness, abundance and specific composition, are directly correlated to microhabitat quality. Thus, bryophytes are able to provide information on the state of health of forestry ecosystems, pointing out where it is appropriate to perform restoration interventions. The analysis of the Sicilian beech woods, carried out using biological and ecological parameters (life form, life strategy, ecological indices, human impact), has emphasized a high rate of bryophyte diversity with more than 170 species, some of which are threatened and candidate to the inclusion in the new European red list. A multivariate analysis was used to examine the bryophyte composition of beech woods, showing a high diversification of the floras of different mountain ranges. Overall, it is a very peculiar bryoflora, when compared with that of other Italian beech forests. Data obtained from ecological and biological parameters are consistent with the climatic, microclimatic and edaphic characteristics of examined woods. The human impact, although not high, is present, mostly on the Etna. Sicilian beech woods, for their peculiarity highlighted also from the bryophyte flora, must be protected and supervised for their persistence over time. Thus, it is necessary to monitor these forests to plan any restoration with a more effective vigilance on Etna beech woods.

\section{Current processes affecting forests and challenges for forestry in Mediterranean area}

\author{
Marco Marchetti \\ University of Molise, Department of Bioscience and Territory, Contrada Fonte Lappone, 86090 \\ Pesche (IS), Italy. E-mail: marchettimarco@unimol.it
}

Keywords: resilience, Mediterranean, adaptive management, monitoring, ecosystem services. 
Forest ecosystems provide several goods and services playing a crucial role in guaranteeing human wellbeing. Particularly, the Mediterranean basin is worldwide recognized as a biodiversity hotspot not only for its environmental characteristics but also for the longtime co-evolution between humans and natural ecosystems, primarily forests. In Mediterranean forests, feedback loops of biotic and abiotic interactions across hierarchical scales create persistent and peculiar scale-specific patterns (e.g. cultural and historical landscapes). In particular, forest management, which traditionally provided a great diversity of products, has slowly focused towards the almost exclusive wood production, thus resulting in a repeated over-simplification of forest stands (e.g. extensive coppice forests or even-aged pure stands). Mediterranean landscapes and related forest stands have thus become simplified, due to either intensification of production systems (both agricultural crops and woods) or as a consequence of land abandonment, wood encroachment, landscape homogenization and desertification. Other than the pure environmental aspects, socio-economic and cultural ones should be even taken into account, being responsible for the loss of cultural other than biological diversity (i.e. referring to Cultural and Natural Capital, respectively).

Land abandonment, ownership fragmentation and increased demand for energy wood are the main societal challenges which affect forests and forestry in Mediterranean context. Moreover, climate change and biodiversity conservation play a crucial role for managing forest ecosystem while improving the potentiality of forests to supply and provide goods and services over space and time. As a consequence, there is the need to develop new adaptive indicators and techniques for the rapid and continuous monitoring in order to enhance forests health and their sensitivity to global changes. The main aim is to improve resilience, resistance and stability of forest ecosystems under uncertain future conditions and in response to the changing socio-economics' need and expectations on natural resources (i.e. ecosystems services).

\section{Resilience in Mediterranean pine forest after recurrent wildfires: new tools to identify the role of restoration}

Leonor Calvo*, Elena Marcos, Victor Fernández-García, José Manuel Fernández-Guisuraga \& Susana Suárez-Seoane

University of Leon, Area of Ecology. Faculty of Biological and Environmental Sciences, León, Spain.

* Corresponding author: leonor.calvo@unileon.es; Phone: 0034987291567

Keywords: Pinus pinaster, wildfire severity, wildfire recurrence, vegetation regeneration, Landsat and WorldView-2 images.

Current predictions of global change effects in the Mediterranean Basin include an increase in the severity and recurrence of wildfires, which may reduce ecosystem resilience, altering the provision of public goods and services. Fire-prone ecosystems, such as Pinus forests, are very susceptible to effects of highly recurrent and severe fires, and in some of them it is necessary to select the most effective post-fire management strategies to increase 
their resilience. In this work we try to analyse the use of satellite images with different spatial resolution (Landsat and WordView-2) to identify the post-fire regeneration of a fire-prone forest ecosystem subjected to different regimes of fire recurrence and severity. Furthermore, we analyze the importance of climax context in the resilience of these ecosystems. To achieve these aims, we selected fire-prone forests dominated by Pinus pinaster and Pinus halepensis that were greatly affected by large wildfires in Spain during 2012, in León and Valencia. We studied 19 structural variables of the vegetation, at the level of Pinus pinasater population and at the level of understorey community through field sampling three years after wildfires. We used reflectance values, spectral indices and first and second order textures from Landsat and Wordview imagery as predictors to monitor vegetation recovery in two scenarios of fire recurrence (High-Low) and severity (High-Low). Main results showed that vegetation recovery models calibrated from WorldView-2 imagery provided high predictive accuracy, both at the level of the Pinus pinaster population and the understory community. All considered post-fire regeneration variables had greater predictability using first or second order textures or ensemble models that integrate spectral indices as predictors along with textures. Landsat- 8 predictors explained better the community recovery. In this type of fire-prone ecosystems, high spatial resolution satellite images can be used in a wide range of research and management applications.

\title{
Forest restoration in Tuscany: from the mountain to the sea
}

\author{
Giovanni Quilghini \& Alessandro Bottacci
}

Corpo forestale dello Stato, Roma, Italia.

*Corresponding author: g.quilghini@forestale.carabinieri.it

Keywords: conservation, Natural State Reserves, alien species.

Since its establishment in 1910, the Special Agency for National Forest Estate (Azienda Speciale per il Demanio Forestale) has aimed at expanding and managing the forest area owned by the State, thus setting the basis of a widespread public property that successively gave birth to Natural State Reserves and many National Parks.

The criteria initially inspiring forest management and restoration were necessarily focused on economics, as a possible tool to solve the social and political problems that historically interested marginal territories, often affected by a lack of infrastructures and the irrational exploitation of natural resources.

The great forest restoration efforts were inevitably impacted by the two World Wars, when forests paid huge tributes to sustain the costs of both conflicts. With the end of WWII, a long period of patient restoration began, during which each property was managed according to a Forest Management Plan.

In recent times, with the institution of Natural State Reserves, productive issues have lost ground to nature conservation policies. Protection and conservation have progressively acquired more and more strength in the cultural background of foresters, alongside with the sustainable use of natural resources. Important initiatives, as the creation 
of the first strict reserve in Italy (Sasso Fratino) and the acquisition of the Montecristo Island (today a natural reserve) to the National Forest Estate, foreran the beginning of national conservation policies.

Nonetheless, the restoration efforts are not yet complete.

This contribution wants to bring to the attention of the scientific and technical community the conservation activities done within the historical fir forests in the Biogenetic Natural Reserve of Camaldoli, recently interested by several extreme atmospheric events that uprooted and broke many trees. Also, we'll illustrate the results of the long-term restoration of priority habitats in the Montecristo Island where, through two LIFE Projects (one concluded in 2014, another ongoing), we focused on limiting the invasion of alien animal and plant species, and on conserving the habitat of animal species with high environmental impact, but of high conservation interest, such as the Montecristo goat.

\section{Restoring oak populations: a case study of applied assisted migration applied on Quercus robur [Po Valley, Italy]}

Fulvio Ducci ${ }^{1 *}$, Roberta Proietti ${ }^{1}$, Giovanbattista De Dato ${ }^{1}$, Maria Cristina Monteverdi ${ }^{1}$, Piero Belletti $^{2} \&$ Enrico Calvo ${ }^{3}$

${ }^{1}$ CREA SEL, Forestry research centre, viale S. Margherita, 80, Arezzo, Italy.

${ }^{2}$ University of Turin, DISAFA, ULF Agriculture genetics, Largo P. Braccini 2, 10095 Grugliasco, Turin, Italy.

${ }^{3}$ Dip. U.O. Servizio per il territorio la montagna e le filiere, Regione Lombardia ERSAF, Via Pola, 12, 20124 Milan, Italy.

* Corresponding author: fulvio.ducci@crea.gov.it; Phone: 00390575353021 - 00393333266077

Keywords: restoration, Quercus robur, pedunculate oak, assisted migration, Po valley.

Pedunculate oak (Quercus robur) and sessile oak (Q. petraea) are widely distributed in fertile valleys and floodplains in Europe. In the Po valley these oaks have been progressively harvested since the Roman age and were sensibly reduced during the 19th century to recover soils for agricultural crops, factories and infrastructures in one of the most productive regions in Italy. Similar situations occurred also in other regions of the Peninsula where these oaks were formerly spread until the hard human influence in the last three, five centuries reduced the huge populations and phragmented the range in small and rare spots. These oaks deriving from a common ancestral taxon are interfertile and partially sympatric, sharing similar habitats, but in different eco-pedological areas. They are interfertile typically unidirectional with pollination from sessile towards pedunculate oak. That explains the sympatrism of both the species and the peculiar adaptive behavior of this complex to water availability. As a consequence, gene flows in the huge oak primary forests were severely reduced or interrupted with losses of fitness and genetic variation. Together with pollution, lowering of the water table and climate change effects, these features make eligible as an example of marginality due to human impact. In the framework of a huge programme to partially re-establish several plain ecosystems in the region, a new secondary oak forest was planted [40.0 ha] in early 2000's in a completely cleaned area, with the aim to obtain a seed source where the remaining Po valley gene pool is collated, to re- 
establish at least partially gene flow connections and to start an experimental field test on assisted migration for future monitoring. After genetic analyses demonstrated the recent interruption of past gene flows, seed material sampled from fifteen different natural English oak populations

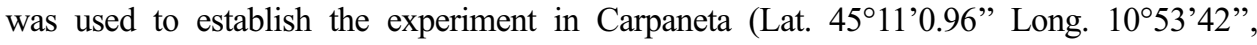
province of Mantua). The objective of this paper is to show the applied of assisted migration study case of Carpaneta forest, how it was projected and structured and its meaning as an experiment on assisted migration in an area considered an ancient diversity hub for this species.

\title{
Differences in ecophysiological responses to seasonal drought of three co-existing oaks in Northern Greece
}

\author{
Filippos Bantis $^{1 *}$, Kalliopi Radoglou ${ }^{2} \&$ Wolfgang Brüggemann ${ }^{1}$ \\ ${ }^{1}$ Institute for Ecology, Evolution and Diversity, Goethe University, Max-von-Laue-Str. 13, Frankfurt \\ am Main, Germany. \\ ${ }^{2}$ Democritus University of Thrace, Pantazidou 193, Nea Orestiada, Greece. \\ * Corresponding author: fbanths@gmail.com; Phone: 00306986617061 \\ Keywords: Quercus ilex, Q. frainetto, Q. pubescens, drought stress, chlorophyll fluorescence.
}

Oaks constitute one of the most common tree genera in Europe with wide expansion under varying environmental conditions. Considering the expected increased drought and heat conditions in future climate scenarios for the Mediterranean region, it is important to identify oak species that are robust under extreme temperatures and drought conditions. The objective of the study was the comparison of the physiological status of three economically and ecologically valuable oak species (Quercus ilex, $Q$. frainetto and $Q$. pubescens) growing under the same environmental conditions in natural coppice stands in NE Greece, in response to seasonal drought stress. The three species co-exist in the same habitat and the studied trees were of similar age and size. Measurements were conducted every 15-20 days until leaf falling between June and September 2016. We studied predawn leaf water potential and fast chlorophyll fluorescence induction curves (OJIP test), chlorophyll content index and relative water content. Meteorological data from the region, such as temperature, precipitation and relative humidity were also collected. Photosynthetic parameters such as PI(abs) and PI(tot) reacted to summer drought conditions, with $Q$. frainetto showing the lowest values as compared to the other two species. The discrepancy between the species increased with duration of the drought period. At the same time, $Q$. frainetto revealed the lowest predawn water potentials. Our results indicate that $Q$. frainetto is less suitable for future forestry applications in the studied climate/elevation zone than $Q$. pubescens and $Q$. ilex.

\section{Phytotoponyms a tool to forest landscape analysis and its transformations. The case study of Calabria (Southern Italy)}

Giovanni Spampinato $^{1 *}$, Rita Crisarà ${ }^{2}$ Piergiorgio Cameriere $^{1} \&$ Carmelo Maria Musarella $^{1}$ 
${ }^{1}$ Department of Agriculture - Mediterranean University of Reggio Calabria, Loc. Feo di Vito, Reggio Calabria, Italy.

${ }^{2}$ Via Trabocchetto 1, Reggio Calabria, Italy.

* Corresponding author: gspampinato@unirc.it; Phone: +39 3288974768

Keywords: phyotoponyms, Calabria, land use change, forests.

Place names provide important information about history, language and human relationships with the land. Phytotoponyms (plant place names) could be used in analyzing current and past distribution of plants and vegetation and to highlight the changes in the land use due to the human impact and/or climate change aimed to support forest restoration. To assess this possibility we have considered all the phytotoponyms related to species and forest ecosystems in Calabria (Southern Italy). As data source we used the official Calabrian topographic maps in scale 1:25,000 and 1:10,000, and the literature data on the Italian toponymy. To interpret place names related to plants and avoid mistakes, we carried out a linguistic and naturalistic joint analysis. We identified 1460 phytotoponyms belonging to 48 forest species and 321 place names related to forests. The most common plants are Castanea sativa (9.7\%), Quercus pubescens s. 1 . (7\%), Salix sp. pl. (6.5\%), Q. frainetto (5.1\%), Q. suber (5\%). All the phytotoponyms were geo-referenced and incorporated into a GIS. Phytotoponyms distribution maps were generated and compared with the current Calabrian forest vegetation, using digital orthophotos, land use maps and literature data. A good correspondence between phytotoponyms and forest vegetation for mountain belt was highlighted, only for $Q$. frainetto we found a reduction in some area. Instead, in the coastal and hilly belt, we observed a significant decrease in the area covered by forest, such as cork woods, thermophilic oak woods and Mediterranean bush, and the disappearance of wet forests with Fraxinus oxycarpa. The spread of phytotoponyms concerning species linked to the forest degradation, as Spartium junceum and Ampelodesmos mauritanicus, highlights an ancient anthropic impact on forests. Overall, the use of phytotoponyms is an important tool to analyze the changes in the vegetation cover. It can provide useful information about restoration of forest ecosystems.

\section{Experiences on good standard density restoration in oak coppices}

Leonardo Nocentini* \& Massimiliano Tancredi Hajny

SIRF, Via. G. Cimabue 16, Arezzo, Italy. E-mail: 1.nocentini@gmail.com; Phone: +393286876300

Keywords: restoration, oak coppices, standard density, sprouting capacity.

The main purpose of the research is to describe effects of silvicultural cuttings in an oak (Quercus cerris L. and Q. robur L.) coppice woodland, with a very high intensity of standards. The number of standards goes up to almost $90 \%$ of the stems, divided in 4 different age classes, with only the remaining $10 \%$ still recognizable as shoots. The number of standards varies from 250 to 300 trees/hectare. The experimental trial, 
applying two different intensities of silvicultural cuttings, tend to regulate the standards density to enhance the sprouting capacity and wood production. This particular reduction of standard density is allowed by forestry regulations only in few Italian regions, due to the assumption that the stump of high diameter will not generate new sprouts. Dendrometric and structural measures brought to an experimental design with two different areas, in which 155 and 120 standards where left standing. All new sprouts on cut stumps were counted and measured in diameter and height for the first three years and finally after 6 years. In both areas, the response in terms of new sprouts on nearly all stumps was positive. The growth rate both in diameter and height, as well as the number of new sprouts, was comparable to data of a normal coppice woodland, also on the largest stumps of old standards. After six years, the mean value of sprouts are $4 \mathrm{~cm}$ in diameter and $5,9 \mathrm{~m}$ in height, on a number of sprouts/stump of 3,8 . Furthermore we observed a mean increment in the diameter of standards of almost 5 $\mathrm{cm}$. Results of measured data are reported.

\section{Prioritization of restoration actions at a regional scale}

Jordi Cortina*, Alejandro Acebal, Antonio Aledo, Andreu Bonet, German Lopez \& Guadalupe Ortiz

University of Alicante-SER Europe, Dept. Ecology and IMEM, Alicante, Spain.

* Corresponding author: jordi@ua.es; Phone: +34 693258878

Keywords: participative restoration, multicriteria analysis, cost-benefit analysis, ecosystem services.

Ecological restoration is an efficient tool to combat land degradation and enhance human wellbeing. Commitments to achieve ambitious large-scale restoration targets have been presented over the last years. The implementation of ecological restoration actions at landscape and regional scales demands the development of planning tools allowing the prioritization of restoration actions. At these scales, most prioritization instruments focus on single habitats and ecological criteria, failing to address land heterogeneity, and incorporate socio-economic and cultural values. We have developed a participative approach to map areas of high priority for restoration in a dry-subhumid to semiarid 224,000 ha-region in SE Spain. The area comprises nine homogeneous landscape units, from wetlands to forests, and various protected areas, and hosts 829,980 inhabitants. We built a platform composed by 88 stakeholders, and surveyed them on the criteria to prioritize restoration actions and the value of ecosystem services they obtain from the different landscape units. Priority criteria, the provision of ecosystem services and economic costs of restoration will be used to map priority areas for restoration. This map will be used as a decision aid tool to discuss the most efficient options for ecological restoration, and engage social actors in ecological restoration programs. 


\title{
Forest restoration in the Mediterranean region of Turkey
}

\author{
Derya Esen* \& Oktay Yildiz \\ Duzce University Faculty of Forestry, Duzce Universitesi Orman fakultesi Konuralp Yerleskesi, \\ Düzce, Turkey. \\ * Corresponding author: deryaesen@duzce.edu.tr; Phone: +905303229515
}

Keywords: afforestation, degradation, environmental, socio-economic.

Turkey stands out with high biological diversity. Undulated topography varying in short distances along with great climatic variation has greatly contributed to this rich biological diversity. In this heterogeneous topography and climate, there exist many fragile forest ecosystems. The Mediterranean part of the country stands out with environmental conditions that are often not very conducive to plant establishment and growth. Typically, this region has long hot and dry summer seasons. Frequent forest fires, drought, soil erosion and sodification are among the ecological stresses in today's forest ecosystems. The Mediterranean Region of Turkey has hosted many civilizations throughout the history. Anthropogenic disturbance has therefore been another major player in the system, shaping up the region's forestlands. There is still considerable human population living in small villages in the forestland in the region. These communities largely depend on forests, agriculture and animal husbandry for living and put pressure on forest resources. Overexploitation, tourism, urban development, grazing, and mining are major issues that Turkish foresters have to tackle and protect already fragile forest resources. The governmental forestry agencies had attempted to address the restoration issues with many expensive afforestation projects in the area, which were however concluded with major disappointment. The agencies has recently changed its approach and begun to implement ecological restoration projects supplemented with socio-economic measures. Natural regeneration supplemented with seedling and planting, converting coppices to high forests, and afforestations through terraces on steep slopes, prioritizing the local forest communities for forestry jobs, afforestation with income-generating native tree species, establishing stands with beekeeping, restoration of pastures within forestlands for grazing, providing loans with no or low interest rates for housing are among the integrated rehabilitation efforts implemented in this region to mitigate the impact of anthropogenic and environmental stresses.

Conservation of forest biodiversity in Sicily: contribution of the University of Palermo Germplasm Bank (Italy)

Franco Palla, Francesco Maria Raimondo \& Anna Scialabba*

University of Palermo, Department STEBICEF, Via Archirafi 38, 90123 Palermo, Italy.

* Corresponding author: anna.scialabba@unipa.it; Phone: +399123891230 
Keywords: germplasm banks, Abies nebrodensis, seed preservation.

Germplasm Banks dedicated to the wild plants seeds conservation play a unique role in integrating the in situ conservation of endemic, rare or endangered plant species. One of the missions of the Seed Bank of the University of Palermo (HBP-Bank) is to support the conservation of biodiversity with particular attention to the spectrum of genetic diversity of plants belonging to Mediterranean habitat. Abies nebrodensis (Lojac.) Mattei is a relict species consisted of 30 natural individuals, gathered in a small area of the Madonie Natural Park in Sicily (1500 -1600 m above s.1.), recorded on the checklist "TOP 50 Mediterranean Island Plants". It is also one of eight conifers species critically endangered because of reproductive biology issues. A. nebrodensis species has been monitored in situ in order to evaluate the state of conservation of natural population and to implement the number of individuals. Its preservation has been integrated since 1994 with ex situ conservation of 83 accessions in the HBP-Bank in the long-term conservation conditions. The scientific strength of HBP germplasm collection is supported by results of several studies on taxonomy, seed biology and genetic diversity.

The embryonic loss observed into seeds produced in natural environment can reduce the genetic variability of germplasm collection. This study, carried out on the A. nebrodensis population, demonstrates that a five-year planning is needed to collect enough seed to represent the genetic variability intra-population. This seed collection scheme can represent a useful tool to apply on other forest endangered species spread in Sicily and in the Mediterranean area.

\title{
Atlas cedar regeneration and structure at forest edges (Djurdjura, Northwestern Algeria): role of microsite and anthropogenic disturbance
}

\author{
Yassina Amirat ${ }^{1 *}$, Fazia Krouchi ${ }^{1}$, Nadia Abdelkrim ${ }^{1}$, Francois Lefevre ${ }^{2}$ \& Arezki Derridj ${ }^{1}$ \\ ${ }^{1}$ Département d'Agronomie, Faculté des Sciences Agronomiques et Biologiques, Université M. \\ Mammeri, BP 17, Tizi-Ouzou, RP 15000, Algeria. \\ ${ }^{2}$ Unité de Recherches Forestières Méditerranéennes, INRA, Avenue A. Vivaldi, 84000, Avignon, France. \\ * Corresponding author: amiratyassina@gmail.com
}

Keywords: Cedrus atlantica, structure, dynamics, anthropogenic disturbance, North Africa.

Cedrus atlantica forest stands are reported (mainly from a floristic perspective) to be subject to anthropogenic disturbance and microclimate constraints regarding the initial regeneration stages, but data on stand structure to illustrate constrains are lacking. The present study is an attempt to provide some data on the regeneration and structure stand at Atlas cedar forest edges.

The study was undertaken on plots of $25 \times 25 \mathrm{~m}$ or $25 \times 50 \mathrm{~m}$. The sampling procedure included the type of cover (pure and mixed Atlas cedar -holm oak stands), elevation (low, intermediate and high) and slope. Structural features (tree height, diameter and density of individuals) were examined on Cedrus atlantica and associated ligneous species within.

The results revealed a structure dominated by Atlas cedar in the overstory, while the understory comprised few trees and shrubs of Quercus rotundifolia, Juniperus oxycedrus 
and Crateagus laciniata. The study evidenced a potential for Atlas cedar extension at the forest edges in situations of low or reduced anthropogenic disturbance. Indeed, we recorded a maximum of 1352 steam/ha in one situation, value that is only exceeded, in the same forest, by recruitments established on a cleared soil following a road realization in 1979. The recruitments observed in our study obviously established in the absence of any direct nurse effect (by common juniper) as may be observed in other situations across the same forest. In less favorable or/and more disturbed situations, we observed a low of 80 steam/ha coupled with very low number of samplings despite of a sufficient reproductive output as indicated by the number of cones recorded on adult trees.

The study highlights the importance of a regeneration strategy aiming at protecting the juveniles until they reach a sufficient size to escape the grazing effects. Eventhough such strategy is unlikely to succeed in the absence of cooperation between forest managers and livestock owners. The importance of bioecological characteristics of white-bark pine (Pinus heldreichii)
for the target seedling production

Vera Lavadinovic*, Vasilije Isajev, Ljubinko Rakonjac \& Zoran Poduška

Institute of Forestry, Kneza Viseslava 3, Belgrade 11030, Serbia.

* Corresponding author: veralava@eunet.rs; Phone: +381-11-3553454

Keywords: white-bark pine, variability, afforestation.

White-bark pine (Pinus heldreichii Christ.), is a Tertiary relict and an endemic species indigenous to the Balkan Peninsula and Southern Italy (Calabria and Basilicata). Investigations carried out in Serbia and Montenegro in natural populations, of this species as well as in plantations 20 - 30 years old and cultivated trees on the green areas in towns, shown that this species exhibits individual and group variation in morphological and genetic characteristics. The same range of variability is present in natural progenies in forests. Significant differences were determinated in nurseries between half-sib progenies in height, average number of branches and increment of seedlings growth at age from two to ten years. In addition, some irregularities of generative reproductions were noticed, such as morphological and functional characteristics of strobiles and occurrence of viviparity. This paper presents the importance of previous investigations for the target seedling production, of white bark pine, intended for the afforestation of unfavorable environmental conditions in highland regions of Eastern Mediterranean.

\section{The use of species in plantations renaturalisation and reforestation in Sicily}

Federico Guglielmo Maetzke*, Donato Salvatore La Mela Veca, Tommaso La Mantia, Emilio Badalamenti \& Sebastiano Sferlazza 
Università di Palermo, viale delle Scienze, 11, 90128, Palermo, Italy.

* Corresponding author: federico.maetzke@gmail.com; Phone: 00393289866185

Keywords: plantations renaturalisation, reforestation, use of species.

Afforestation and reforestation activities in Sicily have been widespread in the last century, in order to increase the forest area that was seriously reduced in the former centuries. Notwithstanding this, Sicily is still characterized by only the $12 \%$ of the regional surface covered by woods and forest. The reforestation in the last century was carried out using conifers and eucalypts, just in order to ensure a quick protection of slopes and pastureland, coping diffuse erosion events, and those intervention had a remarkable success. Nowadays, the target of enlarging the forest areas in the island is still compulsive, but the use of species, considering the actual knowledge and nature consciousness has been completely reassessed basing on the indigenous species. In this view, in order to develop an useful tools for forest plantation planning, in the last regional forest plan the entire regional area was analyzed and ecologically homogeneous areas have been identified to join and target arboriculture and/or forestation plantation activities, to choose tree and shrub species for different environments. The resulted tool was a map of ecologically homogeneous areas and a selection of species suitable for reforestation. After a ten years of implementation and operative use it is useful to enhance those tools by completing the analysis with a specific study aimed to detail the correct use of indigenous species of trees and shrubs. In this work we examined the above described Regional Plan tools and considered the most recent studies on indigenous flora in order to develop a more detailed and locally suitable guide lines to use species both in reforestation and in restoration activities. This last topic is actually compulsory, because of the need of renaturalisation of conifers and eucalypts plantations, that is one of the main target of forestry in Sicily.

\section{The role of phanerogams and cryptogams in the recolonization of cork oak forests crossed by wildfire in Sicily}

Patrizia Campisi*, Maria Giovanna Dia, Francesco Maria Raimondo, Giuseppe Venturella \& Maria Letizia Gargano

University of Palermo, via Archirafi, 38, 90123, Palermo, Italy.

* Corresponding author: patrizia.campisi@unipa.it

Keywords: Cork oakforests, Sicily, post fire recolonization, cryptogams, phanerogams.

The actual distribution and structure of cork oak woods is the result of a process of anthropogenic alteration (utilization of cork, deforestation, coppicing, overgrazing, changes in land use, fire). Additional causes of threats in $Q$ suber woods are pests and fungal disease. Although cork oak is an active pyrophyte the decortication of trunks makes trees more vulnerable to external agents and to fire in particular. Post-fire species are mainly carbonicolous fungi, some Ascomycetes make their appearance after around six weeks while other fungi begin to appear from the second year. The proliferation of fungal hyphae in the ash, as well as of some pioneer mosse protonemata, promotes soil aggregation and 
storage of nutrients. Bryophyte phytocoenoses including species with rapid gametophyte development, spore germination favored by fire or high production of propagules. The association Funarietum hygrometricae is one of the first autotrophic plant communities that are already developing in the first year after the fire in numerous microsites within the forest areas. The dominant species is Funaria hygrometrica, one of the few mosses able to associate with mycorrhizal endophytes, that contribute to strengthen the tolerance (or sensitivity) of plants to passage of wildfire, but also influence the dynamics of regeneration of forest coenoses. Trees of genera Quercus, Pyrus, Fraxinus, Celtis and Arbutus express this dynamic together with some hemiparasites (Viscum, Loranthus) and epiphytes (Polypodium), shrubs (Calicotome, Chamaerops, Citysus, Cistus, Erica, Genista). Additional elements are species of the genera Asparagus, Daphne, Lavandula, Teucrium, Aira, Arisarum, Carex, Eryngium, Inula, Melica. Also parasitic plants (Limodorum, Cytinus), ferns (Asplenium), other bryophytes (Riccia , Bryum, Didymodon, Homalothecium), fungi (Amanita, Russula, Leccinum, Boletus) and lichens (Cladonia) characterize the post-fire forest coenoses in Sicily.

\title{
Analysis of Yew (Taxus baccata) participation to structural features of Atlas cedar forest stands at Chrea (Algeria)
}

\author{
Idir Guechoud $^{1 *}$, Fazia Krouchi $^{1}$, Federico Vessella $^{2}$ \& Arezki Derridj ${ }^{1}$ \\ ${ }^{1}$ Department of Agronomy, Faculty of Biological and Agronomic Sciences, University M. Mammeri, \\ PB 17, Tizi Ouzou, RP 15000, Algeria. \\ ${ }^{2}$ Dipartimento di Scienze Agrarie e Forestali (DAFNE), Universita` della Tuscia, Via San Camillo de \\ Lellis, snc, 01100 Viterbo, Italy. \\ * Corresponding author: guidir56@gmail.com
}

Keyword: Yew, Taxus baccata, stand structure, Atlas cedar forest, Chrea National Park, Algeria.

Yew (Taxus baccata L.) is a rare and endangered species in Europe and North Africa (Morocco and Algeria). There are few studies devoted to this species in Algeria. Therefore there is a need to fill the gap in this regard. This study is a part of a larger project that aims at describing structure of stands where yew is actually present for a better understanding of driving factors likely to determine its regeneration and persistence. In this purpose 21 plots $(25 \times 25 \mathrm{~m})$ were retained for a structural study in a cedar forest (Chrea National Park).

Structural features of Yew were investigated with consideration of some stand parameters i.e. canopy closer, orientation, and slope. Density and size (total height, DBH) were measured on all individuals in the case of Atlas cedar and yew and only on individuals with height $\geq 1.30 \mathrm{~m}$ in the case of other ligneous.

Results indicate that Yew can reach up to $1 / 2$ of the cover height, but participates mostly to midstorey. The other ligneous participate mostly to the under and midstorey, while the overstory is exclusively composed by cedar.

Regarding density, yew revealed to be more frequent under closed canopies, which are in the same time the most favourable to its establishment. 


\title{
Adaptation measures for sustainable forest operations
}

\author{
Woodam Chung ${ }^{1 *} \&$ Enrico Marchi ${ }^{2}$ \\ ${ }^{1}$ Oregon State University, 267 Peavy Hall, Corvallis, United States of America, \\ ${ }^{2}$ Università di Firenze, Dipartimento di Gestione dei Sistemi Agrari, Alimentari e Forestali Firenze, \\ Italy. \\ * Corresponding author: woodam.chung@oregonstate.edu; Phone: +1-541-737-8248
}

Keywords: operational planning, harvesting techniques, worker safety, environment.

Global and regional changes in climate can alter forest ecosystems, disturbance processes, and local work environments, affecting forest operations from tree planting to restoration to timber harvesting. Migration of tree species to higher altitude caused by climate change might expand production forest land areas, but require advanced harvesting techniques for environmentally sound steep ground operations. Widespread damage from extreme weather events, insects and wildfires can increase the occurrence and amount of salvage harvest, but value recovery from damage trees and worker safety could become potential issues. Increased seasonal restrictions on forest operations due to change in local climate require higher operational efficiency in order to maintain the previous production level in a shorter amount of time without compromising worker safety and environment. In areas with increased erosion and landslides, forest operations must be undertaken with more care particularly in regions where more intense rainfall events are anticipated. While the aforementioned shifts can present challenges for many forest practitioners around the world, well-planned adaptation efforts are opportunities in sustainable forest management. In this presentation, we introduce an emerging concept of sustainable forest operations, and suggest adaptation measures for conducting forest operations under the changing climatic environments, hoping that such measures improve the adaptive capacity of forestry sectors while minimizing potential negative consequences.

Selecting surrogate species to improve experience of forest ecosystems in youngest nature-disconnected generations: a framework to select Experiential Key Species.

Corrado Battisti ${ }^{1} \&$ Alessandro Zocchi ${ }^{2}$

1‘Torre Flavia' LTER (Long Term Ecological Research) Station, Protected areas Service, Città Metropolitana di Roma Capitale and Department of Biology, University of Rome III, Rome, Italy. ${ }^{2}$ Independent scientific consultant, Rome, Italy.

*Corresponding author: c.battisti@cittametropolitanaroma.gov.it

Keywords: ecosystems value, education planning, children well-being.

Worldwide, young generations show a larger and larger digital-based behaviour and indoor lifestyle and, mainly in anthropized contexts, their progressive disconnection from 
nature is evident. This fact has important implication in (i) children well-being (observing, exploring, and manipulating natural components they learn about the world around them, developing spatial intelligence, creative- and system-thinking, attitude to problem solving, and reducing physio-psychological Nature Deficit disorders), and in (ii) people awareness of biodiversity and ecosystem values (preventing a digital-distraction from neighbouring ecosystems that, consequently, become neglected ,forgotten, and vulnerable to humaninduced threats). Therefore, it is necessary to know which species are more indicated to improve children's experience and, consequently, pro-environmental behaviours. Here, we propose a simple, quick and explorative framework procedure for the selection of Experiential Key Species (EKS) applicable for sites where check-lists of animal or plant species are available. These species should: (i) be relatively widely distributed and abundant on site, (ii) stimulate a direct experience, and (iii) convey emotions and promote play for their intrinsic eco-behavioural traits. We assumed that experience provided from a species may be considered an event with a proper magnitude, considered as a product of intensity and frequency of occurrence. Therefore, for each species it is possible obtain expert-based scores of Experiential Magnitude on a three-level scale. Knowing the ecology and behaviour of EKS it is also possible to select EKS areas for conservation and education planning. We foster forest scientists and conservationists to improve this procedure of EKS selection in critical contexts, also adding further regime attributes.

\title{
Predicting the current and future potential distributions of Cerdus atlantica in North Africa using Maxent
}

\author{
Abdelkade Bouahmed ${ }^{1 *}$, Federica Vessella ${ }^{2}$, Fazia Krouchi ${ }^{1}$, Bartolomeo Schirone ${ }^{2}$ \& Arezki Derridj $^{1}$ \\ ${ }^{1}$ Faculty of Biological and Agronomic Sciences, University Mouloud Mammeri of Tizi-Ouzou, \\ Algeria. \\ ${ }^{2}$ DAFNE, Tuscia University, Italy. \\ * Corresponding author: a.bouahmed@yahoo.fr
}

Keywords: Cedrus atlantica, North Africa, potential distribution, Maxent, future refugia.

Species distribution models (SDMs) have been widely used in recent years for many purposes. In the present study, we used such tools to predict the current potential distribution of Cedrus atlantica in North Africa where the species occurs naturally and constitutes the most emblematic tree. Future projections of the modeled niche conditions have been applied to inquire about future refugia of the species under anthropogenic climate change following two scenarios of Representative Concentration Pathways (RCPs 4.5 and 8.5) relating to 2070 .

A machine learning method (Maxent) was employed to predict the potential distribution of the species integrating 24 environmental variables. The accuracy of the model was tested using the area under the curve (AUC) of receiver operating characteristic (ROC) method. A jackknife test in Maxent was used to explore the most important environmental variables affecting the species distribution. 
Preliminary results showed a current potential distribution of the species larger than its current geographical distribution, validating the hypothesis that the areas occupied by the species do not fully reflect the environmental potentialities. Future projections of the model revealed a significant contraction of the species potential distribution and even its disappearance in many localities of the Algerian Tell. Future species refugia would be found at high altitudes and in other areas which are not part of its current distribution, e.g. the Moroccan Western High Atlas and Aures region eastward.

Our results are valuable tools for reforestation and emphasize the need to intervene at several levels for the conservation of this endemic species. These mainly include actions to restore degraded cedar forest and an ex-situ conservation strategy according to its future defined refugia, focusing on localities that have demonstrated a high probability of occurrence.

\section{Wood responses to drought in Mediterranean forests: evidences from xylogenesis and functional wood traits in tree-ring series}

Veronica De Micco ${ }^{1 *}$, Angela Balzano ${ }^{1}$, Enrica Zalloni ${ }^{1}$, Giovanna Aronne ${ }^{1}$, Katarina $\check{C ̆ u f a r}^{2}$, Paolo Cherubini $^{3}$ \& Giovanna Battipaglia ${ }^{4}$

${ }^{1}$ University of Naples Federico II, Dept. Agricultural Sciences, via Università 100, Portici (Naples), Italy. ${ }^{2}$ University of Ljubljana, Biotechnical Faculty, Department of Wood Science and Technology, Jamnikarjeva ul. 101, 1000, Ljubljana, Slovenia.

${ }^{3}$ Swiss Federal Research Institute, WSL, Birmensdorf, CH-8903, Switzerland.

${ }^{4}$ Università degli Studi della Campania (ex Seconda Università di Napoli), Dip. Scienze e Tecnologie Ambientali, Biologiche e Farmaceutiche, via Vivaldi, 43, Caserta, Italy.

* Corresponding author: demicco@unina.it; Phone: +39 0812532126

Keywords: Drought, Mediterranean woods, tree rings, xylogenesis, wood anatomy.

The increasing risk for drought stress and heat waves due to expected climate warming have a significant impact on wood formation in Mediterranean species. Decreased wood production can be responsible for the decrease of productivity of Mediterranean forests with negative consequences on related ecosystem services such as carbon fixation in longlasting wood pools. Responses of Mediterranean woods to environmental factors are species-specific: peculiar patterns of cambial activity lead to the formation of intra-annual-density-fluctuations (IADFs) in tree rings which are "positive anatomical anomalies" to cope with intra-annual variations in temperature and water availability.

Here, we analyse xylogenesis and quantify functional wood traits in long tree-ring series in Mediterranean species (Pinus sp. pl., Arbutus unedo and Q. ilex) with intra-annual resolution, linking anatomical parameters with climate. This approach allowed detecting the periods of IADF formation and identifying environmental factors triggering them. Results highlighted the different aptitude of analysed species to form IADFs, which were characterised by different timing of formation, anatomical appearance and ecological meaning. Intra-annual variations of functional wood traits related to efficiency/safety of water transport were consistent with intra-annual variations of carbon stable isotopes 
which are linked with intrinsic water use efficiency. The analysis of xylogenesis and of intra-annual wood anatomical traits, together with information on stable isotopes, proved to be valuable to distinguish between limitations in cell enlargement and cell differentiation due to water deficit or carbon availability. The combination of different kinds of data offered new perspectives in the interpretation of physiological and ecological processes during wood formation. The different sensitivity to environmental fluctuations found in the wood anatomy of the various species should be taken into account in forest management because of its influence on forest dynamics.

\section{Effect of soil compaction on early growth of Quercus robur seedlings since germination}

Barbara Mariotti*, Martina Cambi, Fabio Fabiano, Alberto Maltoni, Andrea Tani \& Enrico Marchi

Università di Firenze, Via San Bonaventura 13, Firenze, Italy.

* Corresponding author: barbara.mariotti@unifi.it; Phone: +393491834158

Keywords: forest operations, seedlings growth, seedling root-system, pedunculate oak.

Negative consequences of compaction can be particularly relevant for seedlings development. Plantlets may delay both germination and penetration of the soil surface by the radicle and the alterations in compacted soil may also affect plants rooting through variations in structural arrangement in attempt to avoid the mechanical obstacle. This study aimed at assessing the soil compaction on growth of Quercus robur seedlings during the first month since germination. The experiment was carried out in a nursery, where compaction was obtained by direct compression of the soil surface on the top of containers using a compression machine in laboratory. In particular, we investigated the effect of soil compaction on morphological attributes of seedlings grown in plastic containers on above and below ground traits during the first month after germination. Three compaction levels were considered (low: $<0.5 \mathrm{MPa}$, medium: $1 \mathrm{MPa}$, and high: $2 \mathrm{MPa}$ ). Results showed significant differences in seedlings traits among treatments and a constraint effect of increasing levels of compaction on early seedlings growth. The effect was particularly detrimental on root system development in depth, thus, it represents an additional critical factor for regeneration establishment, particularly in Mediterranean environments where the early growth stages are crucial to overcome the dry season.

\section{Concerns and evidences on genetic diversity in planted forests}

Vladan Ivetic* \& Jovana Devetakovic

University of Belgrade, Faculty of Forestry, Kneza Viseslava 1, Belgrade, Serbia.

* Corresponding author: vladan.ivetic@sfb.bg.ac.rs

Keywords: planted forests, genetic diversity, reforestation, afforestation, forest reproductive material. 
Planted forests are important source of various services (economic, environmental, and social) with increasing portion in the total world's forest area. Genetic diversity is a fundamental for success and sustainability of planted forests. Facing the concern of reducing of genetic diversity in planted forests, this study offers a review of evidences on comparisons between the levels of genetic diversity in forests established by different regeneration methods. A total of 28 papers comparing genetic diversity in natural forests versus various regeneration methods of 22 tree species examined by the range of markers are reviewed. In the most number of cases there are no significant differences in genetic diversity between natural and planted forests, followed by almost equal number of cases with decreased and increased level of genetic diversity. The loss of rare alleles, but also the new alleles are reported in planted forests. Although the origin of planting material in the most of the cases in unknown, the size of parental population is determinant for the level of genetic diversity in the new forest, with the provenance and seed collection strategy as the most important management practices in planting projects.

\title{
The contribution of historical ecology to functional restoration: case studies from Apennines forests
}

\author{
Gianluca Piovesan ${ }^{1 *}$, Alfredo Di Filippo ${ }^{1}$, Goffredo Filibeck ${ }^{1}$, Irene Tunno ${ }^{2} \&$ Scott Mensing $^{2}$ \\ ${ }^{1}$ Dafne - Università della Tuscia, Via SC de Lellis, Viterbo, Italy. \\ ${ }^{2}$ Deparment of Geography - University of Reno, Office: Mackay Science Mail Stop: 0154, Reno, \\ United States of America. \\ * Corresponding author: piovesan@unitus.it; Phone: +393804999787
}

Keywords: old-growth forests, naturalness degree, chrono-functional indicators, pollen records: historical ecology.

In functional restoration programs, studying of old-growth (OG) stands and historical landscapes is key to describing the reference conditions associated with natural forest ecosystems. A nested historical approach based on high resolution paleoecological reconstructions and dendroecology is needed for the description of complex processes underlying the unique ecological features of Mediterranean landscapes. Tree-ring metrics are able to describe the intensity and time distribution of biological and ecological processes. Treering derived canopy age features (e.g. longevity), disturbance/suppression history and growth trajectories have recently been proposed in a chrono-functional monitoring framework to quantify the naturalness of OG stands. Trees in well-conserved primary OG forests experienced several long suppressions, showing the highest complexity in recruitment history, canopy accession and growth trajectories. In OG beech forests, the best tree-ring metrics were more related to stand structural complexity, than biomass-related metrics. However, tree-ring metrics are site specific (e.g. biogeoclimate dependent) The proposed framework of tree-ring indicators describes functional traits tightly related to forest naturalness and may thus become a tool to provide a benchmark to measure the impact of silvicultural practices or evaluate the effectiveness of ecological restoration. 
Ecological classification of beech forests through tree ring chronologies was found to be congruent with floristic composition patterns. Thus, similarities in tree-ring chronologies of the past between sites might be used to infer analogies in past floristic assemblages, allowing detailed coenological reconstruction at community scale for the last five centuries. Moving to multi-millennial time-scales and to wider spatial scales (landscapes), vegetation reconstruction from fast sedimentation basins allow for detection of forest contraction and expansion phases, and the associated changes in composition, related to socio-economic and techno-cultural changes and/or climatic oscillations. Merging decadal tree-ring information with pollen time series can provide evidences of common climatic/anthropogenic signals, allowing us to disentangle the effects of anthropogenic impacts on forest area from climatic variations.

\title{
Moving towards a definitive high-resolution map of cork oak in the Mediterranean Basin to restoration purposes
}

\author{
Federico Vessella ${ }^{1 *}$, Javier López-Tirado ${ }^{2} \&$ Bartolomeo Schirone ${ }^{1}$ \\ ${ }^{1}$ Department of Agriculture and Forestry (D.A.F.N.E.), Università degli Studi della Tuscia, Via San \\ Camillo de Lellis, snc, 01100, Viterbo, Italy. \\ ${ }^{2}$ Department of Integrated Sciences, Faculty of Experimental Sciences, International Campus of \\ Excellence of the Sea (CEIMAR) and Environment, Biodiversity and Global Change (CEICAM- \\ BIO), University of Huelva, Avda. Tres de Marzo s/n, Huelva-21071, Spain. \\ * Corresponding author: vessella@unitus.it
}

Keywords: Quercus suber, high-resolution punctual map, niche modelling, genetic diversity, forest restoration.

Species distribution, ecology and their roles within vegetation dynamics are basic requirements in conservation planning, which includes restoration and management actions devoted to ensure long-term biodiversity persistence within landscape units or networks at broad scale. However, few tree species were punctually mapped at single-site level. In Europe the only example is Fagus sylvatica, a climacic species not appropriate for reforestation purposes, unless peculiar techniques such as the Miyawaki method are adopted, while pioneer/early successional species are more functional. In the Mediterranean Basin efforts focused on local endemisms or rare species with narrow occurrence, thus easy to map, while the most representative forest species are still a challenge.

Here we attempted an study about Quercus suber L. (cork oak) across the Mediterranean, coordinating the efforts of different workgroups, pre-existing geodatabases and recent field surveys or updates.

Results pointed out a heterogeneous knowledge of the species occurrence, more refined in Italy and Spain, less in France, Portugal and North Africa. However, setting a common denominator of 30 arc-seconds resolution $\left(\mathrm{ca} 1 \mathrm{~km}^{2}\right)$, it was already possible to get a first global distribution of cork oak, made of 155,209 polygons standardized into 75,028 cells at the abovementioned resolution.

These data are encouraging for getting the definitive cork oak punctual distribution in the Mediterranean. 
Feedbacks could be addressed to policy makers, stakeholders and experts interested in conservation and restoration purposes. Further applications, coming from such an output, concern the assessment of the different scenarios of global change and real-world implications of human activities as complementary forces able to alter in space and time the current cork oak occurrence and its genetic diversity, towards modelling approaches. Finally, fragmentation, functional connectivity, potential suitable areas detection and assisted migration could complete the picture leading to a comprehensive knowledge about the species management.

\section{Responses of water use efficiency to drought in Mediterranean forests: evidences from stable isotopes}

Giovanna Battipaglia ${ }^{1 *}$, Paolo Cherubini ${ }^{2} \&$ Veronica De Micco ${ }^{3}$

${ }^{1}$ Università degli Studi della Campania (ex Seconda Università di Napoli), Dip. Scienze e Tecnologie Ambientali, Biologiche e Farmaceutiche, via Vivaldi 43, Caserta, Italy.

${ }^{2}$ Swiss Federal Research Institute, Zuercherstrasse 111, Birmensdorf, Switzerland.

${ }^{3}$ Dipartimento di Agraria, Università di Napoli "Federico II", via Università, 100, Portici, Italy.

* Corresponding author: giovanna.battipaglia@unina2.it; Phone: 00393472373118

Keywords: water use efficiency, isotopes, tree rings, drought.

Water stress is a major determinant of plant species distribution. Extreme climatic events, such as drought, are among the main drivers of forest dynamics and are usually related to forest decline of drought-sensitive tree species, especially in regions, such as the Mediterranean Basin, where water resources are expected to be further limited by climate change. Understanding contrasting drought sensitivity among tree species and how these differences will affect their water and carbon balances is therefore an important topic to forecast responses of Mediterranean forests to global warming and increasing drought stress. Here, we evaluate interspecific differences in intrinsic water use efficiency (WUEi) and the ratio of photosynthesis to stomatal conductance in Mediterranean species (e.g., oak, pines) with different growth strategies and different forest management, using stable isotopes of carbon (d13C) and oxygen (d18O) in annual tree rings. Tree rings are very powerful record of environmental changes occurring during tree growth at annual and intra annual scales. The combination of $\mathrm{d} 13 \mathrm{C}$ and $\mathrm{d} 18 \mathrm{O}$ in tree rings can provide specific information on the underlying ecophysiological processes. Our results indicate consistent differences in WUEi in the analyzed species, largely determined by leaf traits and differences in stomatal conductance control. The stable isotopes approach resulted to be extremely useful to characterize with intra-annual resolution the plant ecophysiological strategies under drought stress, offering new perspectives in the interpretation of physiological and ecological processes. Intra-annual variations of stable isotopes ratio were also consistent with intra-annual variations of functional wood traits related to efficiency and safety of water transport. Our findings can be used to inform selection of tree species and of management practices, allowing maximization of carbon sequestration for a given water budget and minimizing climate change-induced death of trees. 


\title{
Mycoforestry in Sicily: a proposal to enhance the multifunctionality of forests
}

\author{
Maria Letizia Gargano* \& Giuseppe Venturella \\ University of Palermo, Department of Agricultural and Forest Sciences, Viale delle Scienze, Bld.5, \\ I-90128 Palermo, Italy. \\ * Corresponding author: marlega@libero.it; Phone: +393490906252
}

Keywords: mycoforestry, fungi, Sicily.

Mycoforestry is forestry that aims to build on traditional rules to encourage forest ecosystem resilience while creating optimal conditions for fungal communities. Main goals of mycoforestry are: preservation of native forests, recovery and recycling of woodland debris, enhancement of replanted trees, strengthening sustainability of ecosystems, economic diversity. There is a large variety of fungi living in forests, each of which has a specific and complementary relationship to the diversity of native species, the ages of trees, the presence of dead trees or rich forest litter, etc. Fungi are the main responsible of wood decomposition and thus carbon and nutrient cycling, and they also form mycorrhizas in associations with trees and shrubs. The "mycosilviculture" is considered a global and profitable type of silviculture.

Developing adapted forest management practices appears to be means to improve production of prized edible ECM mushrooms such as Boletus and Tuber species and saprotrophic fungi. The first principle for the creation of a mycoforestry system is to utilize native fungal species (i.e. Pleurotus, Ganoderma, Hericium species). Mycoforest technology is a new application to inoculate wild edible and medicinal mushrooms directly in forests. In particular, this technology is able to introduce edible/medicinal mushrooms with high market value directly in forests with the aim to obtain a secondary crop to forests, besides timber. It can be used by private and public enterprises and local administrators interested in developing a wild mushroom harvest industry, to obtain an economic profit from forests or in relation with rural development in forest areas.

\section{Adaptation and restoration of Mediterranean forests: the role of the hidden half}

Antonio Montagnoli ${ }^{1 *}$, Mattia Terzaghi ${ }^{1}$, Gabriella Stefania Scippa ${ }^{2} \&$ Donato Chiatante $^{1}$

${ }^{1}$ University of Insubria, Department of Biotechnology and Life Sciences, via Dunant 3, 21100 Varese, Italy.

${ }^{2}$ University of Molise, Department of Bioscience and Territory, contrada Fonte Lappone, 86090 Pesche (IS), Italy

* Corresponding author: antonio.montagnoli@uninsubria.it; Phone: +39 0332217654

Keywords: fine root dynamics, root morphology and architecture, root plasticity, abiotic stress.

Although the root system represents approximately half of the plant biomass, due mainly to difficulties in methodology, it is still poorly investigated and understood. However, 
the root system provides essential functions to the plant such as anchorage and water and nutrient uptake. Moreover, in order to cope with environmental constrains, plant roots show high plasticity, which can give important information on specific plant adaptation mechanisms. For example, coarse roots displacement shows a clear asymmetry when plant grows on slope conditions. Thus, root plasticity knowledge may implement plant reforestation and/or afforestation activities, such as seedlings establishment, on steep slopes or in those areas where a prevailing wind occurs. Fine roots, which respond to a strict cost-benefit analysis, are fast produced and discarded in a complex seasonal dynamics and modify their development depending on the soil water availability. In this case, in areas characterised by a seasonal drought period, studying fine root compartment may indicate the best species or genotype for an assisted migration approach. Finally, as all models predict a worsening of climate change effects on Mediterranean vegetation, independently from the type of forest restoration strategy that will be adopted, studies regarding how roots will cope and respond to these stressors become of primary importance.

\title{
New approach of aerial seeding to restore Mediterranean mountains: a case of study in Parco Nazionale della Majella (Abruzzi, Italy)
}

\author{
Maria Raffaella Ortolani ${ }^{1 *}$, Massimiliano Marani ${ }^{1}$, Avra Schirone ${ }^{1}$, Gabriele Camillotti ${ }^{2}$, Giampiero \\ Ciaschetti ${ }^{3} \&$ Teodoro Andrisano ${ }^{3}$ \\ ${ }^{1}$ Dipartimento di Scienze Agrarie e Forestali (DAFNE), Università della Tuscia, Via San Camillo de \\ Lellis, snc, 01100, Viterbo, Italy. \\ ${ }^{2}$ Italian National Forest Service. \\ ${ }^{3}$ Ente Parco Nazionale della Majella. \\ * Corresponding author: raffaellaortolani@libero.it
}

Keywords: aerial seeding, reforestation, Parco Nazionale della Majella, forest restoration, Mediterranean mountains.

The planting of the seedlings is presently the main reforestation technique. However, there could be cases in which the seeding is still the more suitable approach due to economic or technical reasons. On the other hand, the seeding is not a solution if difficulties linked to the site access occur. Especially in the Mediterranean mountains, dramatically steep conditions of some terrain make impossible the normal reforestation operations using seeds. For this reason, aerial seeding reforestation is a valid alternative.

We tested a new approach of aerial seeding using a clay shells appropriately modelled to be thrown by helicopters. These shells contain a mix of biodegradable materials that assist the germination.

To check the effectiveness of this clay shells, we selected two areas with Fagus sylvatica L. populations located in Parco Nazionale della Majella (Abruzzi, Italy). These beech forests have suffered severe damage in the summer 2007 because of a fire that affected an area of over 2300 hectares. Since 2010, the Park directorate realized six plots about 1000 square meters in the burned area, almost characterized by steep slopes. In those plots, a plantation of native forest species was carried out and the number and the height of the 
plants were detected every year. Number and the height of coppice shoot of the stumps, resprouting after burnt, were investigated.

To promote the natural vegetation cover, we used the alternative approach using clay shells with Fagus sylvatica L., Acer pseudoplatanus L., Spartium junceum L. and Fraxinus ornus L. seeds. After the thrown by the helicopter, a monitoring phase was carried out to verify the localization of the clay shells, the number of not broken shells and the actual success of seeding.

Although the experimental phase is still in progress, the new technique of aerial reforestation, gave encouraging results. However, further aspects to be analysed about the study of the treatment and preparation of the seeds to be used and the analysis of the mixture within the clay shells are needed.

\title{
Nursery production of wide variety forestry seedlings in order to enhance the biodi- versity and the regeneration success in forest restoration
}

\author{
Kalliopi Radoglou \\ Department of Forestry and Management of Environment and Natural Resources, Democritus \\ University of Thrace, Pnatazidou 193, N. Orestiada, Greece. E-mail: radoglou@fri.gr; Phone: \\ $+306932820875$
}

Keywords: reforestation, regeneration success, semi-arid ecosystems, survival.

That task to maintaining high biodiversity is hard when trying to regenerate disturbed ecosystems, especially under harsh dry summer conditions, which is usually the case for Mediterranean ecosystems. The goal of the restoration efforts is to accomplish the enhancement of biodiversity and the regeneration success through the engagement of innovative new technologies, in nursery production and planting techniques in the field.

Nursery production involves actions such as seed collection of a wide variety of forest species (shrubs and trees) and germination protocols for breaking the dormancy in all these species. Furthermore, growth protocols are needed for many species in order to achieve high seedling quality and guarantee high survival rates after transplanting. Seedlings can grow through the innovative use of the "prototype unit", which is an automated, controlled growth conditions machine that enables the vast production of seedlings through the use of mini-plugs and LED Lamps.

Results are presented for more than 26 forest species produced in the nursery, grown under the standard nursery methods along with seedlings that were grown through the innovative use of the prototype unit. These results on seedling survival were produced from three regenerated sites of Northern Greece, two years after the planting. Results indicate that factors such as characteristics of the regenerated sites as well as species which are aimed to be planted are crucial and determine highly the success of the regeneration effort. 


\title{
Florogenetic origin explains forest resprouting capacity across topographical gradi- ents in peninsular Italy
}

\author{
Camilla Wellstein ${ }^{1 *} \&$ Francesco Spada $^{2}$ \\ ${ }^{1}$ Faculty of Science and Technology, Free University of Bozen-Bolzano, Piazza Università 5, 39100 \\ Bozen, Italy. \\ ${ }^{2}$ Department of Environmental Biology, University of Rome "La Sapienza", Botanical Garden of \\ Rome, Largo Cristina di Svezia 24, 00165 Rome, Italy. \\ * Corresponding author: camilla.wellstein@unibz.it
}

Keywords: resprouting capacity, statistical analysis, environmental features.

Resprouting in tree species plays a crucial role for their survival under conditions of natural disturbance and human impact. Here, we assess for species rich late successional forests across altitudinal gradients on the western side of the Apenninic chain in central Italy the degree of their resprouting capacity. We combined species composition from twenty $400-\mathrm{m}^{2}$ forest plots with information on resprouting capacity for 43 tree species. We analyzed the relationships between resprouting capacity and topographic and climatic variables. The results are based on NMDS ordination, linear models and ANOVA. Based on diverse and relatively chaotic disturbance regimes across the landscapes we expected irregular patterns of resprouting capacity. However, surprisingly, we found clear gradients in this functional trait across the forests. Resprouting capacity of forest stands decreased with increasing altitude from the Tyrrhenian coast to higher elevations. It emerged that resprouting capacity significantly differed between groups of distinct florogenetic origin. Evergreen laurophyllous and sclerophyllous species (paleotropical geoflora) had significantly higher resprouting capacities than deciduous mesophytic species (arctotertiary geoflora). The distribution of these florogenetic stocks along the altitudinal gradient shows a concentration of the evergreen species at lower altitudes while deciduous species are restricted to higher altitudes. The pattern of resprouting capacity of forest stands along altitudinal transects of the central Italian Apennine chain are most likely the legacy of biogeographical historical processes and residuality. Our findings on the landscape-level patterns of forest resprouting capacity have important implications for evaluating the vulnerability towards future climatic and land-use changes.

\section{Forest road planning and maintenance under climate change}

Mika Yoshida ${ }^{1 *}$, Rin Sakurai $^{2} \&$ Hideo Sakai $^{3}$

${ }^{1}$ University of Tsukuba, 1-1-1, Tenno-dai, Tsukuba, Ibaraki, Japan.

${ }^{2}$ University of Miyazaki, 1-1, Gakuen-Kibanadai-Nishi, Miyazaki City, Japan.

${ }^{3}$ The University of Tokyo, 1-1-1, Yayoi, Bunkyo-ku, Tokyo, Japan.

* Corresponding author: yoshida.mika.kf@u.tsukuba.ac.jp; Phone: +81-29-853-4610

Keywords: climate change, LiDAR, road network, soil erosion, watercourse. 
Forest roads are exposed to recent violent climate change, and have suffered, or will suffer unprecedented disasters such as concentrated heavy rain. Since the water drain system has not expected the climate change, it should be upgraded and maintained appropriately not only in the forest roads in little precipitation areas like sub-boreal and/or Mediterranean areas but also in the high-precipitation areas like Japanese climate. For the development of planning and maintenance of forest road, the prediction and evaluation of watercourses is getting important. By using laser imaging detection and ranging (LiDAR) technology, it was easy not only to survey the quantity of earth work by comparing before and after construction of forest road, but also to find the changes of watercourses by road making on the slope surface. The designed water drainage based on the estimated watercourses is effective to predict the collapse area, and useful for efficient maintenance plan. The quantity of collapse on cutting slope was surveyed in a steep mountainous area in Japan comparing with the predicted collapse areas and the effectiveness of maintenance based on the prediction was evaluated.

The use of multipurpose species in forest landscape restoration. The case of Salento (Apulia, Italy)

Tatiana Marras ${ }^{1 *}$, Camilla Wellstein ${ }^{2}$, Domenico Ragno ${ }^{3}$, Agnese Allegrini ${ }^{1} \&$ Bartolomeo Schirone ${ }^{1}$

${ }^{1}$ Dipartimento di Scienze Agrarie e Forestali (DAFNE), Università della Tuscia, Via San Camillo de Lellis, snc, 01100, Viterbo, Italy.

${ }^{2}$ Faculty of Science and Technology, Free University of Bozen-Bolzano, piazza Università 5, 39100 Bozen, Italy.

${ }^{3}$ Agenzia Regionale per le attività Irrigue e Forestali, Regione Puglia, Bari, Italy.

* Corresponding author: tatianamarras@unitus.it

Keywords: reforestation, Mediterranean landscape, multipurpose species, Qurercus suber, Olea europaea.

Many fruit trees show adaptive features and morphological traits that make them suitable for reforestation purposes, e.g. Castanea sativa, Juglans regia, Olea europaea, Prunus dulcis, Prunus avium, Ficus carica, Corylus avellana, Ceratonia siliqua, Pyrus communis and Malus domestica. Considering the role of their wild relatives in vegetation succession, these species might be valuable for forest restoration of Mediterranean landscapes that largely underwent strong and long-term anthropogenic changes. The restoration of the vegetation cover on Corfu Island in the 16th century is such an example. Here, we present the potential use of Olea europaea combined with Quercus suber and Myrtus communis for restoring the tree cover, which recently disappeared largely in Southern Apulia (Salento). Preconditions for this project are: cork oak in Apulia is dying out; following pathogen infestations by Xylella fastidiosa thousands of hectares of olive tree groves have been uprooted; land cover has to be restored to avoid further environmental degradation; olive growers would like to replant olive trees but it is currently forbidden, except the Leccino variety, which is the only one resistant to $X$. fastidiosa; the restored landscape has to show agricultural features to not distort the past landscape but to enable an easy development 
towards natural forest in case of abandonment. Olive tree is a multipurpose species which, when let run wild, is able to perfectly integrate itself in the ecological succession from the Mediterranean maquis to the holm oak forest. Cork oak follows the same dynamism. Therefore, a mixed plantation of olive tree and cork oak might evolve to an evergreen Mediterranean forest with prevalence of holm oak and participation of cork oak and an understory composed of maquis species, such as the myrtle. Southern Apulia is rich in such examples. At a technical level, different plantation models dedicated to finding the optimal plantation density are proposed and discussed, given the heliophily of all the species.

\section{Use of terrestrial laser scanner to monitor structural and biometrical variables in degraded peri-urban forests}

Ugo Chiavetta $^{1 *}$, Gianluigi Mazza ${ }^{1}$, Nicolò Camarretta ${ }^{2}$, Paolo Cantiani ${ }^{1}$, Isabella De Meo ${ }^{3}$, Alessandro Paletto ${ }^{1} \&$ Alessandra Lagomarsino ${ }^{3}$

${ }^{1}$ Consiglio per la ricerca in agricoltura e l'analisi dell'economia agraria, Research Centre for Forestry and Wood, viale Santa Margherita 80, Arezzo, Italy.

${ }^{2}$ ARC Training Centre for Forest Value \& School of Biological Sciences, University of Tasmania, Private Bag 55, Hobart, Australia.

${ }^{3}$ Consiglio per la ricerca in agricoltura e l'analisi dell'economia agraria, Research Centre for Agrobiology and Pedology, via Lanciola - Cascine del Riccio 12/A, Firenze, Italy.

* Corresponding author: ugo.chiavetta@crea.gov.it; Phone: 3289733580

Keywords: terrestrial laser scanner, forest structure, monitoring, forest management, Italy.

Monitoring forest structural features is of key importance, particularly for understanding current dynamics in managing degraded forests. Moreover, in peri-urban forests, it plays the role of direct protection against damages to humans and things caused by increasing extreme meteorological events. In the framework of climate change, the continuous, objective and accurate monitoring of degraded forest structure is a fundamental strategy to assess changes in carbon pools.

New technologies can help reducing time and costs of forest structure monitoring. The Terrestrial Laser Scanning (TLS) is one of the most accurate instruments to measure and assess three-dimensional configuration of physical object.

In this study, we aimed at assessing the efficacy and efficiency of TLS in monitoring degraded forest ecosystem structure and evaluating the impact of forest management practices. We applied the TLS technology in an unstable black pine forest showing different levels of structural problems, located near Florence (central Italy). We tested the feasibility of TLS in extracting the more common structural metrics from 18 permanent sample plots of about $530 \mathrm{~m}^{2}$. Results show that this technology can be used for the proposed aim under certain circumstances. We concluded that the use of TLS in monitoring forest structure and management impact requires each time a specific analysis in order to be operationally feasible, economically convenient and scientifically correct. 


\section{Mediterranean forests: Guidelines for adaptive measures}

Orazio Ciancio $^{1} \&$ Francesco Maria Raimondo ${ }^{2}$

${ }^{1}$ Italian Academy of Forest Sciences, piazza T. A. Edison, 11, 50133 Firenze, Italy. E-mail: ciancio@aisf.it

${ }^{2}$ Department STEBICEF/Section of Botany and Plant Ecology, University of Palermo, via Archirafi 38, I-90123 Palermo, Italy. E-mail: francesco.raimondo@unipa.it

Keywords: protection, management, use, restoration, project, forest expertise, Mediterranean area.

The Mediterranean forests are the result of an ancient and progressive anthropic modification of the original forests; they are the outcome of the millennial and varied forms of use made by man and of his subtraction of the same spaces, mainly for agriculture and urbanization. In recent decades, the primary critical factor of destruction has been the intensification of fires and the increase of their frequency, phenomena facilitated - in some countries in particular - by the depopulation of mountains followed by the abandonment of woods and the upcoming of uncontrolled forms of utilization. The genesis and biological and structural characterization of Mediterranean forests are strongly influenced by climate, and the derived woods are affected by the stress of repeated uses and grazing. At the same time, hot, dry summers and recurrent fires hinder their recovery or reconstruction. Soil loss due to erosion is added to natural and anthropogenic factors. In order to ensure protection to these forests, many countries have adopted active prevention, control and intervention measures; nevertheless, their implementations depends much on the policies of individual governments. Their management, however, cannot be done regardless of a systemic vision and, therefore, by sustainable approaches. More control is needed on the multiple uses of the forest, excluding the traditional uses of wood, aimed at obtaining energy assortments - since many years outmoded by widespread use of fossil fuels and alternative sources - above all on recreational purposes and, therefore, it is necessary to strengthen an active presence on the territory, as well as a more targeted organization and regulation. Finally, the project of restoration of degraded forests - as well as of the re-naturalization of forest stands based on exotic species or reconstitution of a forest - today cannot disregard to follow specific protocols aimed at active conservation of the Mediterranean forests biodiversity - thus, having regard also to its biogeographic structure - as well as to apply systemic silviculture techniques based on floristic and vegetation patterns inferred from phytosociological studies performed in almost all forest communities of the Mediterranean. Forest managing and planning are functions that can never be entrusted to unskilled practitioners, but only to technicians with biological, pedological, ecological and silvicultural expertise: namely, technicians that possess or are able to acquire scientific knowledge and suitable techniques for the delicate task of bringing back nature in the Mediterranean forests or of recreating them, no longer with productive aims but mainly for their environmental value and for the conservation of their biogeographical specificity. Five, then, the main points of discussion of the round table in program: protection, management, use, restoration, project and forest expertise. 


\section{Formal commitments on Zero forest degradation and on deforestation-free supply chain: an effective mean of forest protection?}

Davide Pettenella ${ }^{1}$, Lorenzo Ciccarese ${ }^{2}$, Aynur Mammadova ${ }^{1} \&$ Caroline Sartorato $^{1}$

${ }^{1}$ TESAF Department, University of Padova, Italy.

${ }^{2}$ ISPRA, Rome.

Keywords: zero deforestation commitment, leather industry, supply chain, smallholders, livestock.

Formal commitments by the private sector and governments on degradation-free and zero net deforestation have increased since the 2014 New York Declaration on Forests. Majority of companies with commitments are manufacturers and retailers located in developed countries, while those operating upstream of supply chains and in developing countries still lag behind. Recent scientific studies single out livestock as the largest driver for tropical degradation and deforestation followed by palm oil and timber production. Despite the significant impact and several multiparty initiatives, the sector still lags behind in terms of commitments and policies toward degradation and deforestation free supply chains. The situation is especially dare in Brazil, the biggest cattle producer country in the world, with constant conflict and diverse interests over forest resources.

This study explores the direct linkage between leather industry and forest degradation and deforestation in Brazil by concentrating on the value chain of leather, and analyses opportunities for small scale farmers to adopt deforestation free practices. Vast literature review and application of supply chain governance theories help to identify possibilities and hurdles of adoption deforestation commitments by smallholders.

\section{Opportunities for forest landscape restoration especially in dry lands}

Eduardo Rojas-Briales

Polytechnic University of Valencia, Spain.

Keywords: food security, biodiversity protection, climate change mitigation, bioeconomy.

The traditional approach to reforestation has evolved towards forest landscape restoration (FLR) learning from the previous experiences. The figures published by the GPFLR of available area for FLR without affecting food security are impressive and could reverse considerably the legacy of centuries of deforestation. Overall support for FLR is explained by its multiple wins in terms of soil, water and biodiversity protection, climate change mitigation and adaptation, rural livelihoods and long term renewable raw material supply key for the transition to bioeconomy. In touristic suitable or periurban areas, improving landscape values should be as well considered.

Most of this area is located in dry lands were with exception of the Sahel, deforestation has ceased. In many of the affected countries, fighting against political instability could be 
added to the list of multiple wins of FLR. The recent FAO assessment on dry land forests provides as well very valuable information on the existing forest area.

While the consensus is very solid on FLR many breaks condition to unlock its full potential, especially related to available funds due to the huge area identified. Comprehensive answers are required from physical nature (assisted natural regeneration, cheaper low cover pre-forests, planed lateral expansion, efficient forest fire systems, seed collection facilities, nurseries, agro-forestry, etc.), social (vocational training schools), institutional (public forest services), legal (forest tenure), financial (identifying additional sources) and market (out grower schemes). It should be recalled that a chain breaks in its weakest point and there for a full coverage approach is preferable. While focusing on forest area enlargement, preserving and managing the existing forests is the best tool for forest area enlargement both from a physical and social perspective.

Grazing as a conservation tool for priority habitat types in Prespa National Park and the case study of $* 9562$ - Grecian Juniper woods: philosophy, implications and opportunities

Irene Koutseri*, Anna Logotheti \& Vassiliki Roumeliotou

Society for the Protection of Prespa, Agios Germanos, Prespa, Greece.

* Corresponding author: i.koutseri@spp.gr

Keywords: priority habitat types, Grecian juniper woods, conservation measures, agro-environmental schemes.

Habitat type $9562 *$ Grecian Juniper Woods (GJWs) found within the Prespa National Park (PNP) in Greece has been classified as priority, according to the EU Habitats Directive (92/43/EEC) and is one of the 7 priority habitat types of the PNP that depend on grazing for their conservation.

The abandonment of traditional agroforestry practices leading to the encroachment of broadleaved species on GJWs, has been identified as the main threat to the habitat. The EU LIFE12 NAT/GR/539-JunEx project on GJWs has been designed so as to use the approach of rangeland science, where specific guidelines have been developed in order to use sustainable grazing as a tool towards the restoration and improvement of functions of the GJWs. Based on these guidelines, pilot actions are currently being implemented.

The ultimate goal of this approach is to provide the opportunity to relevant stakeholders (e.g. stock-breeders) and competent local authorities to appreciate the returns from habitat conservation and sustainable implementation of grazing and forestry practices. Regarding implementation of grazing, the project beneficiary, the Society for the Protection of Prespa (SPP), a locally-based NGO, promotes this approach through collaboration with primary sector cooperatives and local authorities/stakeholders for the all priority habitats in need of grazing within the PNP.

Primary sector activities and conservation management are promoted as complementary activities for sustainable habitat management. At the same time streamlining of national policies and EU policies and funding opportunities for the agricultural and the conserva- 
tion sectors is locally recognized as a tool and several joint local initiatives prepare the ground for the development of relevant agro-environmental schemes.

Although hands-on conservation and local initiatives are producing results, integration of EU policies within relevant national legislation and practice is facing obstacles rendering the sustainability of project actions uncertain.

\section{Anticipating climate change and transforming degraded forests: The billion hectare challenge}

John A. Stanturf*

US Forest Service, 115 kingston way, Athens, United States of America. E-mail: drdirt48@gmail.com; Phone: 0017062028066

Keywords: Bonn Challenge, adaptation management, assisted migration, learning organization.

Restoring forest ecosystems is an increasingly important task for forest science globally, where an estimated 2 billion hectares are deforested or degraded. Urbanization, rising income and consumption levels, and other social disruptions present contradictory pressures on use of forest land. Additionally, climate change, particularly extreme weather events, increases the need for active restoration. Forest Landscape Restoration is promoted as a long-term process to meet the billion hectare challenge by regaining ecological integrity and enhancing human wellbeing. A strict reading of ecological integrity, however, means to restore to pre-degradation species composition and forest structure. Rapidly changing environmental conditions, exacerbated by extreme weather events, may render past conditions maladaptive. A focus on restoring function and enhancing resilience is at the core of adaptation strategies for coping with climate change. Strategies may be incremental, anticipatory, or transformational. These strategies vary in their orientation toward future conditions but share similar objectives of favoring genotypes adapted to future climate; resisting pathogens; managing herbivory and invasive plants to ensure adequate regeneration; encouraging species and structural diversity at the stand or landscape levels or both; and providing connectivity and reducing fragmentation. Unfortunately, knowing when to act is more of a challenge than what to do. Nevertheless, management actions that differ from traditional practices could face significant social and organizational resistance. Thus, adaptive and nimble organizations are needed to that can anticipate climate change and meet the billion hectare challenge. Such organizations will have developed future scenarios, planned responses in advance of extreme events, and put in place monitoring adequate to provide early warning of changing mean conditions.

\section{On the forest restoration times}

Orazio La Marca ${ }^{1 *}$, Monica Notarangelo ${ }^{2} \&$ Nicola Moretti ${ }^{3}$ 
${ }^{1}$ Università degli Studi Firenze, via S. Bonaventura 13, Firenze, Italy.

${ }^{2} \mathrm{CRA}$, piazza Nicolini, Trneto, Italy.

${ }^{3}$ Università Studi Basilicata, via dell'università, Potenza, Italy.

*Corresponding author: lamarca@unifi.it; Phone: +393407739076

Keywords: natural, evolution, thinning, Turkey-oak, coppice.

The Authors, based on observations carried out for about 20 years in a Turkey-oak abandoned coppice, within a protected area of Gargano, examine some dendrometric parameters in comparative sample plots, respectively subjected to forest management (with two increasing thinning intensity) or left to natural evolution. Analysis of data shows that after seventeen years plots thinned with very strong intensity have lower standing volume with respect to plots thinned with strong intensity, even if the gap is reducing over time. Anyway, all managed plots have had noticeable growth and yield, with low mortality rate for either oaks and other tree species. Conversely, plots left to natural evolution have had the worst performance in terms of growth and yield to such an extent that plots thinned with strong intensity currently have the same standing volume. Furthermore, the high mortality occurred has strongly reduced the number of other tree species as well as that of oaks.

\section{Monitoring of soil carbon and nitrogen cycling in degraded forest after thinning intervention for ecosystem restoration and climate change mitigation}

Alessandra Lagomarsino ${ }^{1 *}$, Kalliopi Radoglou ${ }^{2}$, Foteini Doukalianou ${ }^{3}$, Alessandro Elio Agnelli ${ }^{1}$, Gianluigi Mazza ${ }^{4}$, Ugo Chiavetta ${ }^{4}$, Isabella De $\mathrm{Meo}^{1} \&$ Michail Orfanoudakis $^{2}$

${ }^{1}$ Consiglio per la Ricerca in Agricoltura e l'analisi dell'economia agraria (CREA) Research Centre for Agrobiology and Pedology (CREA-ABP), via di Lanciola 12, Firenze, Italy.

${ }^{2}$ Democritus University of Thrace, 69100, Komotiní, Greece.

${ }^{3}$ DAMT - Xanthi Forest Directorate, Prof. Rossidi 1, Xanthi, Greece.

${ }^{4}$ Consiglio per la ricerca in agricoltura e l'analisi dell'economia agraria, Forestry and Wood Research Centre, viale Santa Margherita 80, Arezzo, Italy.

* Corresponding author: alessandra.lagomarsino@crea.gov.it; Phone: 0552492240

Keywords: carbon, climate change mitigation, soil.

Forests ecosystems generally act as a net sink for carbon, contributing to climate change mitigation by removing atmospheric $\mathrm{CO}_{2}$ and storing it in different carbon pools (i.e. biomass, soil, deadwood, litter). Forest degradation, implying a decrease in canopy cover and regeneration, as well as forest fragmentation, contribute to atmospheric green-house gas (GHG) emissions through decomposition of remaining plant material and soil carbon. These larger emissions are no more balanced by the $\mathrm{C}$ storage capacity in woody biomass and soil, due to unstable structural conditions of the degraded stands. In this context, the restoration of degraded pine forests derived by plantation with the aim to reestablish and improve the natural functioning processes, offer a cost-effective means to mitigate climate change, both 
reducing emissions from deforestation and forest degradation and increasing carbon removals. FoResMit project aims at quantifying the mitigation potential of innovative forest management, including sources and sinks for GHG. Two Mediterranean coniferous forests have been selected in Italy (monte Morello, Tuscany) and Greece (Xanthi forest, Thrace) and subjected to traditional and innovative thinning, compared to un-managed forests.

Comprehensive data on $\mathrm{C}$ storage potential of degraded pine forest and $\mathrm{GHG}$ emissions are lacking. To cover the existing gap, not only $\mathrm{CO}_{2}$, but also $\mathrm{CH}_{4}$ and $\mathrm{N}_{2} \mathrm{O}$ emissions have been monitored for the first months after thinning. The contribution of deadwood to GHG emissions has been measured in laboratory and in the field. Carbon and nitrogen pools of mineral soil and forest floor have been monitored before and after the thinning intervention. Litter fractions have been separated in un-decomposed, fragmented and humified and their carbon and nitrogen content measured, to follow litter degradation process.

The influence of environmental variables (site conditions, temperature, moisture) on pools and fluxes has been evaluated, and first results showed a high relevance compared to forest management.

\section{Eucalyptus plantations in Italy and forest rehabilitation: the way towards a sustainable management}

Giuseppe Pignatti ${ }^{1 *}$, Gianni Facciotto ${ }^{2}$, Giulio Sperandio $^{3} \&$ Stefano Verani ${ }^{1}$

${ }^{1}$ Council for Agricultural Research and Economics (CREA-PLF Roma), via Valle della Quistione, 27, Roma, Italy.

${ }^{2}$ Council for Agricultural Research and Economics (CREA-PLF), Strada Frassineto, Casale Monferrato, Italy.

${ }^{3}$ Council for Agricultural Research and Economics (CREA-ING), via Pascolare, Monterotondo, Italy.

* Corresponding author: giuseppe.pignatti@crea.gov.it; Phone: +39 661571034

Keywords: Eucalyptus plantations, forest rehabilitation, sustainable forest management, Italy.

Since the beginning of the twentieth century Eucalyptus species have been planted in the Mediterranean regions of Italy, in order to achieve several purposes: reforestation of degraded agricultural land, reduction of soil erosion, wood production, social (lower unemployment) and other environmental benefits. Soon a debate emerged on the advisability to plant exotic species as Eucalyptus and the difficulty to manage the plantations in order to reestablish native forest vegetation. Nowadays forest rehabilitation of Eucalyptus plantations could be an opportunity to improve forest products and services, but strongly depends on the ecological and productive conditions of the forest stands.

In the framework of a Ministry of Agriculture Food and Forestry Policies financed project (FAESI), we analysed National Forest Inventory (INFC2005) data belonging to stands where Eucalyptus sp. pl. were present. In the 87 plots, distributed in 7 Regions of Italy and classified into 10 different forest types, the stand volume varies widely, with a mean of $71 \mathrm{~m}^{3} / \mathrm{ha}$. In all the plots Eucalyptus is predominant in volume to other forest species, in $60 \%$ of the plots it is the only tree species present. Pinus halepensis, originally planted together but capable also of 
regeneration after fire, is the most frequent native tree species. Less than $36 \%$ of the plots have regeneration and only in $46 \%$ of the plots shrubs are present.

Considering the overview given by NFI data, we made three different hypotheses for forest rehabilitation in order to improve the capacity of Eucalyptus plantations to deliver forest products and services. Plantations could be managed as usual for timber and biomass purposes, or completely replaced by planting different native forest species, or managed following principles of continuous cover forestry to expand social and environmental functions. Each option has different starting requirements and outputs in terms of products and services, as well as conditions of technical and economic feasibility which are discussed.

\title{
A new collaborative project on the Caspian forests of Iran: a gene pool for the adap- tation of European forests?
}

\author{
Palle Madsen ${ }^{1 *}$, Khosro Sagheb-Talebi ${ }^{2} \&$ Ole Kim Hansen ${ }^{1}$ \\ ${ }^{1}$ Dept. of Geosciences and Natural Resource Management, University of Copenhagen, Nødebovej \\ 77A, 3480 Fredensborg, Nødebo, Denmark. \\ ${ }^{2}$ Research Institute of Forests \& Rangelands (RIFR), P.O.Box 13185-116, Tehran, Iran. \\ * Corresponding author: pam@ign.ku.dk; Phone: +4540453019
}

Keywords: Refugial population, genetic diversity, adaptation potential.

Refugial populations of several European tree species are expected to have more genetic diversity and greater adaptation capacity than European populations of these species in general. This phenomenon has been described for European silver fir (Abies $a l b a)$. Compared with 17 other European provenances across its natural range, a Calabrian provenance showed superior growth and health in Danish provenance trials established in the 1930s and inventoried at age 44. It was the southernmost provenance tested in these field trials located more than $500 \mathrm{~km}$ north of it northern distribution limit. Similarly, the Caspian forest in Northern Iran can be considered an important refugial area in relation to European species of rich deciduous forests covering 1.8 million ha. The Caspian forest holds a rich species diversity that includes both many European species as well as several closely related species. We present at recently initiated collaborative research project that aims for exploring and documenting the genetic diversity and adaptation potential of Caspian provenances compared with commonly used Danish or European provenances in Denmark. One of the main research challenges and goals are to uncover whether the case of Calabrian silver fir is unique or if a similar superior adaptation potential exists within the refugial populations of other tree species which are native or closely related to native European species. 
From afforestation and reforestation to forestoration, from goods to services. How science and society can shape the transition

\author{
Lorenzo Ciccarese $^{1} \&$ Davide Pettenella ${ }^{2}$ \\ ${ }^{1}$ ISPRA - Institute for Environment Protection and Research, Division for Species and Habitat \\ Conservation and Land Sustainable Management, Rome, Italy. \\ ${ }^{2}$ TESAF Department, University of Padova, Italy.
}

Keywords: ecosystem services, science, society.

Despite the increasing recognition and attention from industry, government, the media, and private citizens to ecosystem services provided by forest ecosystems, global deforestation and forest degradation rates remain alarmingly high: global forestland base is shrinking at a rate of 13 Mhay- 1 and only $1 / 5$ of the world's old growth original forest cover remains intact. Both the extent and quality of forest habitats continue to decrease and the associated loss of biodiversity jeopardizes forest ecosystem functioning and the ability of forests to provide ecosystem services. Against this backdrop, it is of major importance not only to conserve but alsoas stated inter alia by the UN Convention on Biological Diversity, the Agenda 2030 for Sustainable Development, the Paris Agreement and the EU Seventh Environment Programme - to restore forest ecosystems. This is why there is increasing interest worldwide in the science and practice of forest restoration, we define forestoration.

In step with the theories and principles of restoration ecology, forestoration has its major focus on restoring the relation between biodiversity and forest ecosystem functioning. Under this perspective forestoration includes establishment of short-rotation, single- or multiple-species, plantations on abandoned or degraded soils (while offering little improvement of biodiversity), reclamation planting on former mining soils, where abiotic factors limit establishment and growth of native vegetation, restoration plantings in secondary forests or assisted regeneration in selectively logged forest. Forestoration can be achieved either through controlling pressures on forests, such as fires, invasive species or unsustainable harvesting, or through techniques to accelerate forest recovery such as planting programs or attracting seed dispersers. These activities all have in common that they consist of active and intended management interventions, whilst forest natural succession is regarded as unintended, nor prescribed or directed by humans.

The objective of this paper is to analyze the current and future role of science and society in shaping the transition to wide ambit of forest restoration approaches, with a view to enhancing the full range of benefits they can provide and delivering transformative change for landscapes and people. The paper, while recognizing the key role of the forest sector in restoration efforts, emphasizes the need to integrated different disciplines and sectors, particularly agriculture, soil science, energy, economics and sociology, to formulate sustainable forestoration policies and planning processes. Public participation, involving landowners as well as the general public, will be a key factor in the forest restoration planning process. The scope of forest restoration should always be defined with the support of local people as this is a prerequisite for any successful investment. 


\section{Restoration and sustainable management of beech (Fagus sylvatica) stored coppices in North Western Italy}

Renzo Motta ${ }^{1 *}$, Roberta Berretti ${ }^{1}$, Pierpaolo Brenta ${ }^{2}$, Fabio Meloni $^{1}$, Antonio Nosenzo ${ }^{1}$, Pier Giorgio Terzuolo $^{2} \&$ Giorgio Vacchiano ${ }^{1}$

${ }^{1}$ Dip. DISAFA, University of Turin, Largo Paolo Braccini 2, Grugliasco, Italy.

${ }^{2}$ IPLA, C.so Casale 476, Torino, Italy.

* Corresponding author: renzo.motta@unito.it; Phone: ++39 0116705538

Keywords: silviculture, sprouting, conversion, restoration, neglect.

In northwestern Italy most beech forests have been traditionally coppiced until the recent past due to the high request of firewood and wood charcoal. Over the last decades, however, local and global socio-economic changes have caused a decline in firewood exploitation. As a consequence in beech coppices there has been lenghtening of rotations or neglect. The beech is highly sensitive to the lengthening of the rotation due to its poor sprouting capacity. In the last 40 years, the main way to contrast this trend has been a systematic conversion from coppice to high forest throughout repeated thinnings. Because most of such silvicultural treatments required are costly, and the entire conversion process lasts many decades, this policy is not sustainable yet. In the Piedmont region, only half of the existing 135.000 ha of beech forests are actively managed of which about 7000 are still coppiced and more than 60.000 ha are currently stored coppices or coppices under conversion to high forest.

In this study we have: a) analyzed the sprouting capacity of the beech in different forest types and age classes; b) analyzed the availability of different timber assortments in mature and stored coppices; and c) tested new economically sustainable silvicultural approaches to ensure and enhance continued provision of ecosystem services requested from the forest.

Results about sprouting capacity and timber assortments and preliminary results about silvicultural treatments are presented.

\section{Conservation of the biodiversity and sustainable restoration of cork oak Maamora forest (Morocco)}

Mohamed Fennane ${ }^{1}$, Francesco Maria Raimondo² \& Mohamed Rejdali ${ }^{3 *}$

${ }^{1}$ Institut scientifique, Université Mohammed V, Avenue Ibn Batouta, B.P 703, Rabat, Morocco.

${ }^{2}$ Department STEBICEF, University of Palermo, via Archirafi 38, I-90123, Palermo, Italy.

${ }^{3}$ Institut Agronomique et Vétérinaire Hassan II, Madinat Al Irfane, B.P. 6202, Rabat, Morocco.

* Corresponding author: m_rejdali@hotmail.com

Keywords: Quercus suber, conservation, North Africa.

The Maamora forest (Morocco) is by far the largest existing cork oak forest in one stand throughout the world distribution area of Quercus suber. During centuries, it has played 
major ecological, economic and social roles, staring in stable from the wide expanse of sandy soils, prone to wind erosion, there by stopping the spillage of sand (sandstorms to Europe). For this reason, as well as for the many beneficial effects on the stabilisation of local population and the improvement of the economy of the region, it becomes necessary to launch an effective recovery action and reforestation through interventions funded and supervised by the national and international organizations.

The world largest cork oak Maamora forest is located at the Moroccan Atlantic plain between Rabat and Kenitra cities. It has a potential area of around 300.000 hectares of cork oak trees, that turned nowadays to a low density tree cover of less than 50.000 hectares, with a very disturbed or even absent climax environment. Research programs and scientific articles related to this magnificent forest are various and deal with all its aspects: ecologic, floristic, faunistic, socio-economic, and cultural. The future of the Maamora forest, however, causes much concern despite the many initiatives and efforts made to protect, conserve and rehabilitate its ecosystems. Both decision makers and managers failed to refrain this rapid regression and decline of this forest caused mostly by heavy and anarchic human pressure.

The authors try to present an outcome of the current situation and presume that nature by itself and through fencing as well as assisted regeneration might be the appropriate way to meet the challenge. Our contribution is a synthetic review of some of the work done about the Maamora forest and the initiatives made to safeguard this important forest ecosystem with many habitats and an excellent biodiversity.

\title{
Assessing forest logging soils disturbance by multi-temporal analysis of ground high resolution model derived by Portable Laser Scanner and physical parameters sampling
}

\author{
Martina Cambi*, Francesca Giannetti, Davide Travaglini, Gherardo Chirici \& Enrico Marchi \\ Università di Firenze, Italy, Firenze, via San Bonaventura 13, Firenze, Italy. \\ * Corresponding author: martina.cambi@unifi.it; Phone: +393331467155
}

Keywords: forest logging, soil disturbance, precision forestry, PLS, Terrestrial Laser Scanner.

Forest operations may lead to negative consequences in terms of compaction and rutting, which may result in soil degradation processes such as erosion, mudflow and landslides. The damage depends on type of vehicle, number of passes, ground morphology, soil properties and slope. The aim of this research was to investigate the impact on soil caused by logging operations through ground survey and with terrestrial portable laser scanner (PLS). Samplings were carried out in two trails that differed for the numbers of machine passes and slope. The data collection where performed before and after works to analyze the impact on soil of forest operations. The specific objectives were: (i) to analyze how forest operations have influenced soil compaction and rutting; (ii) to assess soil compaction with traditional techniques; iii) to determine logging caused rutting with high-resolution ground surface models generated by PLS scans; iv) to assess the differences in the soil disturbances in two different trials. Significant impacts were detected with both investigation 
methods, i.e. physical parameters and multi-temporal analysis of high resolution ground surface models derived by PLS. Therefore, in order to limit the damage to the soil, it is important to apply extraction methods and machines in relation with the specific site conditions, especially when a high mechanization level is used.

\section{Innovating forest plantation practices: science, technical development and knowledge} exchange

Catherine Collet ${ }^{1 *}$, Claudine Richter ${ }^{2}$, Erwin Ulrich $^{2} \&$ Marieke Blondet $^{1}$

${ }^{1}$ INRA, INRA, LERFOB, Champenoux, France.

${ }^{2} \mathrm{ONF}$, Fontainebleau, France.

* Corresponding author: catherine.collet@inra.fr; Phone: 33383394043

Keywords: plantation, barrier to innovation, mechanical site preparation.

Forest plantation is a major tool to adapt forest ecosystems to global change and to restore damaged forest ecosystems. However, several barriers to a wide use of plantation to regenerate or restore forests have been identified:

1. Recurrent failure of plantation under certain site conditions (dry sites, sites with high vegetation competition,...).

2. High financial plantating costs.

3. Potential negative environmental impacts of planting (soil compaction, biodiversity loss,...).

4. Hard working conditions for tree planters.

The different barriers need to be removed, in order to promote the use of plantation as an adaptation tool. New plantation practices, with enhanced technical, economic, environmental and social performances must be developed and promoted among forest practitioners.

Mechanical tools have been developed in recent years, that improve the different performances of plantation practices. Examples of such innovation will be shown. The analysis of the innovation process highlights the weaknesses of regional and national socio-technical networks, in relationship with poor knowledge exchange practices, and poor economic collaboration among stakeholders within the local forest sector. Developing stronger socio-technical networks, based on information and financial collaboration, is a key to the development and diffusion of new planting methods.

\section{Geobotanical foundations and diversity patterns in the Mediterranean forests}

\section{Francesco Spada}

Department of Environmental Biology, University of Rome "La Sapienza", Botanical Garden of Rome, Largo Cristina di Svezia 24, 00165 Rome, Italy. E-mail: francesco.spada@uniroma1.it 
Keywords: Mediterranean forests, lauriphyllous dendroflora, specie adaptations, community structure.

Mediterranenean forests are very diverse ecosystens, ranging from sclerophyllous evergreen thickets and woodlands, to stands of warm-temperate deciduous forests and nonboreal conifer forests at higher altitudes.

Since they host most of the woody species of the European flora, their assessment is highly suggestive for the structure and long term history of the whole Mediterranean biota.

Nearly all are home to a changing amount of modern sclerophyllous derivatives of the lauriphyllous dendroflora of the subtropical forest biomes spread over the southern part of Paloeurope at the onset of the Neogene. This suggests an overall high degree of abaptation and relictuality in their structural assessment, a pattern mirrored, among others, by the complex genetical structure of the present day dominating oaks, whose intriguing incongruence between molecular signatures and morphological traits reveal reiterated paleorange pulsations and late-Neogene adaptation events to the present day seasonal, warm, dry Mediterranan-type climatic regime.

Here focus on this legacy on coenology is emphasized in order to explain in terms of historical events features usually misinterpreted as result of human impact, disruption theories, the role of fire and a general reductionistic actualism in the interpretation of species adaptations and community structure in the Mediterranean regions.

The controversial direction of sucession in Mediterranean forests is outlined on this basis, in order to contribute to a florogenetically and biogeographically consistent descriptive model for their restauration.

\section{MEDFORVAL, the Mediterranean network of forested areas of high ecological value: restoration, protection or management of woodlands sites}

Magda Bou Dagher Kharrat ${ }^{1 *}$, Marine Lovero ${ }^{2 *}$, Valentine Pleiss ${ }^{2}$, Pedro Regato Pajares ${ }^{3}$ \& Alain Chaudron $^{2}$

${ }^{1}$ MEDFORVAL, France, Marseille, 14 rue Louis Astouin, 13002 Marseille.

${ }^{2}$ Association internationale forêts méditerranéennes (AIFM), France, Marseille, rue Louis Astouin, 13002 Marseille.

${ }^{3}$ AIFM consultant, Spain, Madrid, General Ampudia 4, 28003 Madrid.

* Corresponding author: marine.lovero@aifm.org; Phone: 009613468260

Keywords: network, ecological value, Mediterranean region, international, forest restoration.

The high ecological value of some Mediterranean forest and wooded areas results from the interaction between many natural and human factors, following a very complex dynamic. The MEDFORVAL project is financed by MAVA Foundation for Nature and is managed by AIFM (International Association for Mediterranean Forests) as part of the Collaborative Partnership on Mediterranean Forests (CPMF) and the Strategic Framework on Mediterranean Forests (CGFS). It aims to create collaboration between practitioners and policy makers from different sectors of the Mediterranean on concrete measures to protect, manage or restore the ecological values of their respective sites, through network- 
ing. After the two first years, the network is rich of 19 sites spread over the entire Mediterranean basin and grouped into four ecological clusters. These sites, helped by the network Secretariat, have started working together, through regular meetings, learning exchange visits and the development of joint project proposals. This presentation will feature experiences on ecological restoration shared by MEDFORVAL network members such as: Shouf biosphere reserve restoration plan - Lebanon; Participation of private owners to the restoration of the Guadiana watershed - Portugal; Juniper landscape restoration in Prespa national park - Greece; Rehabilitation of the Jordan river valley - Jordan and Restoring the Ticino valley ecological connectivity - Italy. Challenges encountered in different ecological restoration of Mediterranean forests projects will also be discussed. Some thoughtful scientific questions are raised aiming to optimize economically and technically the restoration outcomes: explore and restore the below-ground biodiversity, promote the use of native species, clarify the effect of nurse-plants and their "facilitation" role, select the appropriate genetic resources to be used for reforestation, evaluate the effect of fencing on restored site biodiversity and finally the deciphering the effect of animal wildlife on the long-term sustainability of restored forests.

\section{Spatio-temporal patterns and drivers of secondary succession in a Mediterranean landscape}

Rafael Da Silveira Bueno ${ }^{1 *}$, Daniel Garcia ${ }^{2}$, Mauro Galetti $^{3} \&$ Tommaso La Mantia ${ }^{1}$

${ }^{1}$ University of Palermo, viale delle Scienze, Ed. 4, Palermo, Italy.

${ }^{2}$ University of Oviedo, E-33071 Oviedo, Asturias, Spain.

${ }^{3}$ Sao Paulo State University, Av. 24A, Rio Claro, Brazil.

* Corresponding author: rafabrc@yahoo.com.br; Phone: +39 3347422239

Keywords: herbivory, GIS, Mediterranean, natural regeneration, secondary succession.

In recent years, many Mediterranean agricultural lands have been abandoned, reforested, rewilded and ecologically restored, creating different templates and trajectories for the development of secondary succession. Our objective was to verify whether past legacies of woody vegetation (remnant forest and shrub patches and reforestations) influenced the current spatial pattern of woody cover in a midsuccessional Mediterranean area, identifying spatial cold and hotspots (i.e: low/slow or high/fast cover increase) and looking for footprints of seed-disperser and herbivore-mediated processes at landscape and local scales. The study took place in three $500 \times 200 \mathrm{~m}$ plots in a formerly managed and partially reforested pastureland in the Ficuzza Natural Reserve (Palermo, PA), the last large forest remnant in western Sicily. We sampled woodland and shrubland cover over a 24 -year interval (from abandonment to the present), by combining current field sampling and a GISbased interpretation of sequential high resolution satellite images and greyscale aerial photographs. The overall woody vegetation cover almost doubled through the studied period, with a balanced increase of woodland and shrubland patches. Fraxinus angustifolia reforestation contributed marginally to woodland expansion, while the major increase was due 
to the natural regeneration consisted mainly of five fleshy-fruited and one dry-fruited species, all of them well protected against herbivory. Most of woody cover expansion was correlated with initial cover, although some hotspots presented $100 \%$ of cover increase from bare areas even further than $100 \mathrm{~m}$ away from any woody patch. Our results reveals that the composition and spatial configuration of past vegetation legacies can influence the secondary succession evolution, as well as the specific contribution of natural regeneration, human-made reforestation, herbivory and animal seed dispersal in creating these patterns, setting a template for further investigations regarding mechanisms and functional traits driving these patterns.

\title{
The contribution of forest restoration to the conservation of woody endangered species in Sicily
}

\author{
Cristina Salmeri ${ }^{1 *}$, Francesco Maria Raimondo ${ }^{1} \&$ Gianniantonio Domina ${ }^{2}$ \\ ${ }^{1}$ Dept. of Biological, Chemical and Pharmaceutical Sciences and Technologies, University of \\ Palermo, via Archirafi 38, I-90123 Palermo, Italy. \\ ${ }^{2}$ Dept. of Agriculture and Forest Sciences, via Archirafi 38, I-90123 Palermo, Italy. \\ * Corresponding author: cristinamaria.salmeri@unipa.it; Phone: +3909123891228;+393388381177
}

Keywords: forest biodiversity, endangered species, nursery production, restoration, Sicily.

Sicilian forest ecosystems are, in general, numerically poor in terms of their floristic composition. As many studies on Sicilian dendroflora have highlighted, such poorness is not intrinsic to forest formations, but it is due to the millenary human pressures. Repeated passage of fire, continuous wood usage and reforestations by single or few species dramatically reduced the plant biodiversity of Sicilian forest ecosystems, often suffering of monodominance. The Sicilian dendroflora includes several endangered species, such as Abies nebrodensis, Betula aetnensis, Celtis tournefortii subsp. asperrima and subsp. aetnensis, as the wild pears, which in Sicily are represented by 4 endemic species, in addition to the commonly known Pyrus spinosa and P. pyraster. Similarly, the genus Salix counts 8 different species instead of the given 4 . Thus, higher attention toward all these taxa, which strongly improve the forest heritage of specific areas, is needed. Throughout their knowledge, survey, propagation and extensive use, the risk of local and general biodiversity loss can be limited. These actions necessarily require a targeted nursery program aimed to produce plantlets with high genetic variability starting from local propagation material.

\section{Radial increment of Taxodium distichum from Veliko ratno ostrvo area (Belgrade- Serbia) at two different heights of the trunk}


Faculty of Forestry, Kneza Viseslava 1, Belgrade, Serbia.

* Corresponding author: dusan.jokanovic@sfb.bg.ac.rs; Phone: 065-6969-846

Keywords: Veliko ratno ostrvo, Taxodium distichum, radial increment, soil characteristics.

Taxodium distichum is exotic species that is mainly recommended for afforestation of lowland areas in Serbia, such as Veliko ratno ostrvo. This area has been characterized by flat orography with an average height of about 72 meters above the sea level. In the paper, there were analyzed growth rings characteristics of three trunks that have been chosen as representatives, due to their dimensions, physiological and healthy looking, position in the population and due to lack of any technical deformation. Radial increment was measured at two heights - on the base and on 1.3 meters (breast height). On the base of the obtained results, it was deduced that growth rings were a bit wider on the base than on the breast height. It was also concluded that an average width of the growth rings by Taxodium distichum (about $3.5 \mathrm{~mm}$ ) was a bit bigger than by the other conifers in Serbia. It is very important to emphasize that radial increment of Taxodium distichum depends a lot on soil characteristics. As for Veliko ratno ostrvo area, it belongs to alluvium with different texture. Big water capacity related to suitable soil texture and significant content of nutrients, as well, caused relatively wide growth rings. The most important conclusion could be related to following: minimal growth rings width is situated in juvenile wood zone, that includes the first 10 growth rings; maximal growth rings width was in the last a few growth rings, close to the bark; culmination of radial increment is remarkable at about age of 30 .

\title{
Mapping and monitoring in protected natural areas: the use of the FAO LCCS as an effective tool for habitat mapping and change detection
}

\author{
Valeria Tomaselli $^{1 *}$, Giuseppe Veronico ${ }^{1}$, Cristina Tarantino ${ }^{2} \&$ Palma Blonda $^{2}$ \\ ${ }^{1}$ CNR IBBR, via G.Amendola 165/A, Bari, Italy. \\ ${ }^{2}$ CNR IIA, via G. Amendola 165/A, Bari, Italy. \\ * Corresponding author: valeria.tomaselli@ibbr.cnr.it; Phone: 3393137493
}

Keywords: mapping, monitoring, change detection.

Effective and timely biodiversity monitoring within protected sites and their surroundings is critical for detecting landscape changes which might impact site's conservation status, quality and resources and to evaluate the effectiveness of conservation policies in protecting biodiversity and ecosystems from human activities. The most commonly used Land Cover/Land Use (LC/LU) or habitat classification systems are limited in their ability to read all aspects of the landscape. The Food and Agricultural Organization (FAO) Land Cover Classification System (LCCS) taxonomy (Di Gregorio and Jansen, 2005) was identified as the most appropriate for providing a common language for harmonizing different LC/LU legends. One of the basic principles of this system is that a given land-cover class is defined by a dynamic combination of classifiers, thus allowing the more complex 
semantics of each land-cover class may be described. FAO/LCCS has been also found to be effective for translating EO-derived LC/LU classes to habitat types (Tomaselli et al., 2013; Adamo et al 2014), since it allows a better description of natural habitats in comparison to other classification systems. Furthermore, LCCS has proven to be a valid tool in change detection, both at the level of conversion and modification. In fact, changes become immediately identifiable by a difference in classifier, or through the use of additional classifiers, although maintaining the same class type. In this contribution LC and habitat mapping have been performed on a site belonging to the Natura 2000 and located in Southern Apulia (Italy), characterized by coastal environments, Mediterranean maquis and extensive pine forests. The mapping was performed by means of photo interpretation and on-site survey, in years 2007 and 2015. Different LC and habitat classification systems were used and results compared. The LCCS turned out to be the most effective in detecting changes in forest types, highlighting changes such as height and density which were not evidenced with other classification systems.

\section{Changes of forest communities surface in the Murge of Taranto (Puglia - Southern Italy) in the last 60 years}

Roberto Greco*, Maria Immacolata Marzulli, Manuela Persia \& Patrizia Tartarino

DiSAAT - Università degli Studi di Bari Aldo Moro, via Orabona 4, Bari, Italy.

* Corresponding author: roberto.greco@uniba.it; Phone: +393347408035

Keywords: Forest communities, Murge, Southern Italy.

The Planning of Forest Community Management must be necessarily based on the knowledge of the functioning of present ecosystems, but also of relations that exist or that occurred in the past with the surrounding area and that led to the current disposition.

In this study, changes of forest vegetation surfaces occurred in the last 60 years were examinated in an area extended on about $55.000 \mathrm{ha}$, located in the Murge of Taranto in Puglia (Southern Italy). It consists of the river basins that underlie the "Gravine" (ie. deep cuts in the limestone and calcarenite units in the area) of Ginosa, Laterza, Montecamplo and Castellaneta.

The study began with the GIS based photo-interpretation activity of ortophotos dating back to 2006-2011, validated by field surveys, aimed at the vectorization of the different classes of Land Cover (Directive 2007/2/EC - artificial surfaces, agricultural areas, woods and forests) in the studied area. For the forest vegetation it was used a classification of physiognomic-type composition, considering a unit digitalisation of 0,2 ha.

Subsequently, the vector database obtained was compared with the aerial photo frame of 1954-55, orthorectified and georeferenced with the software Pix4dMapper. Therefore, it was possible to vectorize differences on surfaces observed, and evaluate, also on a statistical basis, factors that have determined them. 


\section{Quercus suber in the Iberian Peninsula: ecological characteristics and cork exploitation}

Javier López-Tirado $^{1 *}$, Federico Vessella ${ }^{2} \&$ Pablo J. Hidalgo ${ }^{1}$

${ }^{1}$ Department of Integrated Sciences, Faculty of Experimental Sciences, University of Huelva, Avda. Tres de Marzo s/n, 21071 Huelva, Spain.

${ }^{2}$ Department of Agriculture and Forestry (D.A.F.N.E.), Università degli Studi della Tuscia, via San Camillo de Lellis, snc, 01100, Viterbo, Italy.

* Corresponding author: javier.lopez@dbasp.uhu.es

Keywords: Quercus suber, Iberian peninsula, ecology, cork, Species Distribution Models.

The current distribution of cork oak (Quercus suber L.) is located westwards in the Mediterranean Basin: from Portugal to Italy in Europe and Morocco, Algeria and Tunisia in North Africa. The largest stands are distributed in the Iberian Peninsula, especially in Portugal and Southwestern Spain. The ecology of cork oak is characterised by thermophilous areas ranging from sub-humid to hyper-humid environments. Acid soils are also particularly linked to this oak. The abovementioned conditions altogether make cork oak more competitive than Q. ilex subsp. ballota (Desf.) Samp. (holm oak). By contrast, the latter shows a greater ecological plasticity like indifference to edaphology and withstanding both more arid and colder conditions as well.

Human-induced disturbances and management since several centuries ago has led to an alteration of the land use. Cork oak has suffered opposite shifts on its distribution. For instance, in Southern Spain holm oak has been favoured to the detriment of cork oak in savannah-like pasturelands (locally called dehesas in Spanish or montados in Portuguese), due to the sweet acorn of the former for feeding porks. More recent business like eucalypt (Eucalyptus globulus Labill.) plantations has devastated potential areas for cork oak -eucalypts are needed of a high amount of annual rainfall--. On the other hand, in the surroundings of the Strait of Gibraltar, Algerian oak (Q. canariensis Willd.) has been disadvantaged with respect to cork oak. In this case, it seems that cork has prevailed because there is no a clear exploitation resource from Algerian oak. Nowadays, Portugal is the first producer of cork in the world.

Recent studies on Species Distribution Models (SDMs) point out a gradual decrease of the potential distribution of cork oak in Southern Spain. This methodology is highly useful for being aware about the trend of this species in a context of global change. Suitable spots can be detected aiming to carry out conservation programmes. Thus, ecologic and economic issues could be achieved to this significant Mediterranean oak.

Toward sustainable forest management in Morocco: restoration, certification and regional program as cases

Said Lahssini ${ }^{1}$, Mustapha Naggar ${ }^{2 *} \&$ Said Moukrim ${ }^{2}$

${ }^{1}$ ENFI, Bp 511, Tabriket, Sale Morocco, Rabat, Morocco.

${ }^{2}$ HCEFLCD, 3 Rue Haroune Rachid, Agdal-Rabat, Rabat, Morocco. 


\footnotetext{
* Corresponding author: munaggar@yahoo.fr; Phone: +212663666596

Keywords: forest management, forest restoration, sustainability.
}

Morocco's ecological contexts are diverse. As such, altitude varies from sea level to $4100 \mathrm{~m}$, the geology is diverse, and rainfall ranges from less than $30 \mathrm{~mm} \mathrm{year}^{-1}$ in the south to more than $2000 \mathrm{~mm}_{\text {year }}^{-1}$ in the north. As consequence, Morocco is one of the most diverse countries of the Mediterranean region in terms of plant species. It houses the most species in North-Africa with 4200 floral-taxa, including 1282 subspecies, representing 920 genera and 130 families (Fennane \& al. 2012). The most important part of such biodiversity are hold in mountainous area and mainly in forest domains which covers 9 million ha. In order to ensure the sustainability of the goods and services provided by forest lands, forest management adopted by Moroccan forest administration has been widely adapted to cope with the multiple uses of Moroccan forests. Moreover, under climate change perspective on which Morocco is expected to be severely impacted, sustainability of forests and its associated resources are a key factor for ensuring inhabitants' survival and adaptive capacity and requires to improve approach for managing forests. Then a holistic approach to address the various components of Moroccan forests and to ensure their suitability while taking into account the effects of climate change that includes tree regeneration and reforestation efforts and the livelihood of the local community depending on it, is needed. This communication, through the analyses of three Moroccan context aiming to implement sustainable forest management [(1) regional forest program (regional planning of Rifs' forests), (2) forest management certification (certification FSC of Itzer's forest management process), (3) forest restauration as main driver of forest management (case of Maamora)], try to underpin the main changes adopted to forest management practices and the main challenges to forest suitability while taking into account the effects of climate changes.

\section{The coastal communities of Junipers in Sicily: conservation status and perspectives} of management and restoration

Pietro Minissale ${ }^{1 *} \&$ Saverio Sciandrello ${ }^{2}$

${ }^{1}$ Department of Biological, Geological and Environmental Sciences, University of Catania, via A. Longo, 19, Catania, Italy.

${ }^{2}$ Centre for the Conservation and Management of Nature and Agroecosystems (CUTGANA), University of Catania, via Santa Sofia, 98, Catania, Italy.

* Corresponding author: p.minissale@unict.it; Phone: 3404175175

Keywords: Juniperus sp. pl., threatened habitats, restoration actions, Mediterranean dunal environments.

Juniperus sp. pl. plant communities represent one of the most threatened habitats of the Mediterranean area. Notably they are Juniperus oxycedrus subsp. macrocarpa coastal vegetation, growing on the highest and stable dunes, and Juniperus turbinata plant community, which colonizes the inner dunes. Especially in northern Mediterranean this psam- 
mophilous vegetation suffered a strong decrease due to the intense coastal urbanization and agricultural activities which/and sometimes have expanded to the coast occupying dune environments. These wooded plant communities, climax-vegetation of dune environments, are included in Annex I (2250* code) of the European Habitats Directive 92/43. Their importance is related also to the vulnerability of the species which show slow growth and limited renovation capacity. The creation of protected areas has favored the conservation, of these habitats, even though delayed. Regarding this topic Sicily represents a case study, because the disappearance and transformation of extensive dune systems have occurred in a period of just half a century. Dramatic examples are the coastal dunes of Catania and Gela. Another threat and alteration in coastal dunes were the reforestation actions with alien species, such as Acacia.

\section{Poster presentations}

The longevity and resilience of Pinus leucodermis: a long tree-ring chronology to investigate the Mediterranean climate

Anna Dinella $^{1 *}$, Ingo Heinrich ${ }^{2}$, Alfredo Di Filippo ${ }^{3}$, Michele Baliva $^{3}$, Aldo Schettino ${ }^{4}$, Giuseppe De Vivo $^{4} \&$ Gianluca Piovesan ${ }^{3}$

${ }^{1}$ Faculty of Science and Technology, Free University of Bolzano-Bozen, piazza Università, 539100 Bolzano, Italy.

${ }^{2}$ GFZ German Research Centre for Geosciences, Telegrafenberg, 14473 Potsdam, Germany.

${ }^{3}$ Department of Agriculture and Forestry Science (DAFNE), Università della Tuscia, via San Camillo de Lellis, 01100 Viterbo, Italy.

${ }^{4}$ Pollino National Park, Complesso monumentale Santa Maria della Consolazione, 85048 Rotonda, Italy.

* Corresponding author: anna.dinella@natec.unibz.it: Phone: +39 3315008388

Keywords: Bosnian pine, longevity, resilience, tree-ring, climate change.

Bosnian pine (Pinus leucodermis Antoine) is one of the longest-lived species of Europe. This biological feature allows building long tree-ring chronologies. The aim of this study is to analyze the growth responses of long-lived trees of Bosnian pine that grows at higher altitude limit of the Monte Pollino and Serra Dolcedorme (Pollino National Park, Southern Italy). We used the dendrochronological method to measure both ring-width and wood anatomical parameters. Dendrochronological results show that the reduced growth rates promote the longevity of Bosnian pine. Despite their old age, trees do not show a growth decline, but an increasing trend of growth in the last decades. The recent positive growth trend represent an important deviation from the sigmoid model of tree growth. A positive correlation has been obtained by comparing the growth of trees, in terms of basal area increment (BAI), and the trend of temperature measured in the last 150 years. It follows then an absence of the tree growth reduction in the oro-Mediterranean pine forests in response to global warming. The same comparison has been carried out using the main 
wood anatomical parameters (e.g. lumen area, lumen diameter) which point out a strong relationship with climatic trend. The Bosnian pine behavior in relation to temperature variations allowed to investigate the climatic events which characterized Mediterranean region in the last decades and it represents an effective indicator of the current climate change. Furthermore, this study underlines the remarkable acclimatization and resilience of the pioneer Bosnian pine, which makes it suitable for forest restoration of mountain Mediterranean degraded areas. In the context of mitigation strategies for carbon sequestration, restored Bosnian pine stands, thanks to the high tree longevity of the species, will sequester carbon for centuries.

\section{Analysis vegetation of Juniperus oxycedrus subsp. badia microforests in the Iberian Peninsula: increasing their knowledge for a better restoration}

Carmelo Maria Musarella ${ }^{1 *}$, Ana Cano Ortiz ${ }^{2}$, José Carlos Piñar Fuentes ${ }^{2}$, Sara Del Río ${ }^{3}$, Carlos José Pinto Gomes ${ }^{4}$, Giovanni Spampinato ${ }^{1} \&$ Eusebio Cano $^{2}$

${ }^{1}$ Department of AGRARIA - "Mediterranea” University of Reggio Calabria, Loc. Feo di Vito, 89122 Reggio Calabria, Italy.

${ }^{2}$ Department of Animal and Plant Biology and Ecology, Section of Botany - University of Jaén, Campus Universitario Las Lagunillas s/n - 23071 Jaén, Spain.

${ }^{3}$ Department of Biodiversity and Environmental Management (Botany), Faculty of Biological and Environmental Sciences - University of León, Campus de Vegazana s/n, E-24071, León, Spain.

${ }^{4}$ Department of Landscape, Environment and Planning; Institute for Mediterranean Agrarian and Environmental Sciences (ICAAM); School of Science and Technology - University of Évora, Rua Romão Ramalho, n 59, P-7000-671 Évora, Portugal.

* Corresponding author: carmelo.musarella@unirc.it; Phone: +39 09651694374

Keywords: Junipers, conservation, edaphoxeric conditions, restoration, livestock.

Juniperus oxycedrus L. is widely distributed throughout the Mediterranean region. In the Iberian Peninsula three subspecies are recognized: subsp. macrocarpa (Sm.) Ball on coastal sandy dunes, subsp. badia (H. Gay) Debeaxu and subsp. oxycedrus in internal territories.

Our studies show that the latter two subspecies grow on hard substrates, both acidic and basic, and they coexist in the same territories. Communities of $J$. oxycedrus subsp. badia occur in a wide territory in the centre and south of the Iberian Peninsula, prefer rocky substrates and are favoured by forest fires and more xeric environments. These communities host many endemic species that are important for biodiversity conservation.

The study highlighted several types of plant communities linked to different ecological conditions. Many of these communities are significantly degraded. The current grazing management is leading to a reduction of these communities. High livestock pressure of cervids and lagomorphs increases the content of organic matter: all this causes an involution of this vegetation type. However, only a grazing control it is not sufficient and other measures must be taken for forest restoration. When xericity of substrate is changed, Pinus halepensis, Quercus rotundifolia and Quercus coccifera compete with Juniperus oxycedrus. Therfore, selective cuts could be planned to enhance juniper wood, following forest 
restoration patterns proposed by Valle \& al. (1990: $1^{\text {a }}$ Reunión sobre el Medio Ambiente en Andalucía.) and Cano \& al. (1994: Naturalia Baetica 6: 7-112). They propose a dynamic pattern based on a first diagnosis of: initial vegetation stages, objectives pursued, methods of management and actions. This pattern allows to get the final stage which is a plant community of Juniperus oxycedrus subsp. badia with an edaphoxerophylous character.

\section{Strategies for the re-naturalization of reforestation: the case study of the Sicilian clay hills}

Tommaso La Mantia ${ }^{1}$, Donato Salvatore La Mela Veca ${ }^{1}$, Giulia Casamento ${ }^{2}$, Angelo Dimarca ${ }^{2}$, Giuseppe Giaramida ${ }^{2}$, Giovanni Landini ${ }^{3}$, Giuseppe Pace $^{3} \&$ Rafael Da Silveira Bueno ${ }^{1 *}$

${ }^{1}$ Dipartimento Scienze Agrarie e Forestali, Università di Palermo, viale delle Scienze, Edificio 4, Ingresso H, Palermo, Italy.

${ }^{2}$ Legambiente Sicilia - Gestione Riserve Naturali, via Tripoli, 3, Palermo, Italy.

${ }^{3}$ Regione Siciliana, Dipartimento Sviluppo Rurale e Territoriale, Ufficio di Trapani, via Vallona, 6, Trapani, Italy.

* Corresponding author: rafaeldesilveirabueno@unipa.it

Keywords: Mediterranean reforestation, Eucalyptus plantations, Pinus plantations.

On the IX century there was a massive reforestation effort in Sicily aiming to contrast increasing hydrogeological problems. Most of these reforestation were made using conifers or exotic species, and despite the overall cover increase, nowadays several of these areas still remaining in the past regarding richness and density of natural regeneration. Our objective was to evaluate the effectiveness of a naturalization intervention in the Natural Reserve "Grotta di Santa Ninfa", located in western Sicily. The first step was structurally characterize the 30 year eucalyptus reforestation, composed by Eucaliptus camaldulensis. The sampling areas consisted of circular plots ranging from $567 \mathrm{~m}^{2}$ up to $1270 \mathrm{~m}^{2}$ and densities ranging from 238 up to 673 trees ha- ${ }^{-1}$. Moreover, all woody plants of other species were identified and quantified. In winter, after the characterization, within sampling area, all eucalyptus trees were cut and 904 seedlings from 18 species were planted along the cleared areas. Each seedling was classified accordingly to its general integrity before planting. The first verification of planting success was made after 5 months, and was registered an average mortality of $6 \%$, with species specific mortality ranging from $0 \%$ up to $33.3 \%$. One year later another verification was made, and the average mortality reached $52.6 \%$, ranging from $11.1 \%$ up to $90 \%$. The negative initial conditions of the seedlings were positively correlated with post plantation mortality, demonstrating that for some species there is low probability of correcting initial problems like inappropriate size, age or deformations of the root system. The low density of natural regeneration demonstrating that in some areas active interventions are needed to enhance the naturalization speed of reforested areas. Results of this test together with results of previous tests at Santa Ninfa provide important information on ways to proceed with the re-naturalization of reforestation in Sicily. 


\title{
Genetic variability of Austrian pine (Pinus nigra) seedlings in response to water deficit and its important to reforestation in arid terrain
}

\author{
Vasilije Isajev $^{1 *}$, Milan Mataruga ${ }^{2 *}$, Rakonjac Ljubinko ${ }^{1}$, Vera Lavadinovic ${ }^{1} \&$ Aleksandar Lucic $^{1}$ \\ ${ }^{1}$ Institute of Forestry, Kneza Viseslava 3, Belgrade, Serbia. \\ ${ }^{2}$ Faculty of Forestry, University of Banja Luka, Bulevar Vojvode Stepe Stepanovica 75a, Banja Luka, \\ Bosnia \& Herzegovina. \\ * Corresponding author: veralava@eunet.rs; Phone: +381113553454
}

Keywords: indicators of drought, Pinus nigra, properties of seedling.

Knowledge of genetic adaptation to environmental factors can help develop strategies for successful reforestation in arid terrain. In this study, Austrian pine (Pinus nigra Arnold) seedlings grown from seed collected from 40 open-pollinated families from five Balkan Peninsula provenances were evaluated for survival and growth under imposed drought. Within each provenance, seed was collected from an extremely harsh habitat and from a favorable habitat. One-year-old seedlings, from each provenance, habitat type and open pollinated family were transplanted into three "stressbeds", each designed to simulate different levels of water availability by filling with varying ratios of crushed stone and soil. Seedling height growth and survival were recorded every 20 days from April-September. In all provenances, seedlings grown from seed originating from the harsh habitats had lower survival regardless of stressbed treatment compared to those grown from seed collected from favorable habitats. Cluster analyses of survival data showed that populations from a similar habitat generally grouped together, regardless of provenance. The lowest and highest survival values were found in seedlings from harsh habitats, while those from the favorable habitats clustered in the mid-range. These results suggest that higher seed quality from productive stands may be the most influential factor determining seedling vigor under drought stress and that genetic adaptation to drought was not detected in adjacent populations having different habitat conditions.

\section{In defence of biodiversity and Mediterranean landscape: the "Carta dei Comuni custodi della macchia mediterranea"}

Aurelio Angelini ${ }^{1}$, Francesco Cancellieri ${ }^{2}$, Renato Carella ${ }^{3}$, Giuseppe Lo Paro ${ }^{4}$, Vincenzo Piccione 5 , Francesco Maria Raimondo ${ }^{6} \&$ Salvatore Scuto $^{7}$

${ }^{1}$ Department of Architecture, University of Palermo, viale delle Scienze, Ed. 14, 90128 Palermo, Italy.

${ }^{2}$ Associazione Centro Educazione Ambientale (CEA) Messina onlus - c.da Castellaccio Le Terrazze snc - 98122 Messina, Italy.

${ }^{3}$ Associazione Ramarro Sicilia, Via A. Ferrari 2, 95041 Caltagirone, Italy.

${ }^{4}$ Department CHIMBIOFARAM, University of Messina, via Stagno d'Alcontres, 98166 Messina, Italy.

${ }_{5}^{5}$ Department of Biological, Geological and Natural Sciences, University of Catania, via Longo, 95100 Catania, Italy. 
${ }^{6}$ Department STEBICEF/Section of Botany and Plant Ecology, University of Palermo, via Archirafi 38, I-90123 Palermo, Italy.

${ }^{7}$ Soprintendenza per i Beni culturali e ambientali di Caltanissetta, Caltanissetta, Italy.

* Corresponding author: aurelio.angelini@libero.it

Keywords: Mediterranean maquis, nature protection, municipalities, Sicily.

In Sicily, the "macchia mediterranea" extending 110,000 hectares, i.e. $21 \%$ of the whole woody area, is the most emblematic and representative plant coenosis. In the world, it is also an important biodiversity reserve because, in front of its low territorial extenction just $2 \%$ - the macchia, together chaparral, fymbos and other similar coenoses, includes more than $20 \%$ of total plant and animal species to date observed.

The charter of guardian municipalities of Mediterranean maquis was conceived by a group of Sicilian scholars and environmentalists for years engaged in the protection of nature. The goal is to form a network of municipalities that become "guardians" of the Mediterranean maquis, committing to develop programs to protect the rich naturalistic heritage present in Sicily. The safeguard comes from the need to make a prevention sylviculture to stop the anthropic exploitation, the land consumption, contrast the fires, mainly arsons, abuses related to pasture and to incompatible uses with the preservation of its landscape and biodiversity. To date, 30 municipalities have decided to adhere to the project. Among them, there are Caltagirone - the place of the first presentation of the project and signing of the first 11 adhesions - Bagheria, Buccheri, Caltanissetta, Comiso, Gela, Messina, Palermo, Palazzolo Acreide, Syracuse, etc. Other 10 municipalities have ongoing the deliberative acts for their adhesion; among them, Catania.

This is an initiative destined to cross the regional borders and it has already generated interest also in other municipalities of southern Italy and Sardinia.

In addition to the text of the project and the overview of the potential and real extension of the Mediterranean maquis in Sicily, the relevant plant associations, a summary of the main floristic prominences, as well as the mapped role as an important factor with respect to mitigation and resilience to climatic changes (drought and desertification) are presented. Moreover, the list of participant municipalities and the graphical representation of the areas of their respective competence are reported. The list of the events organized by the promoting group for the diffusion of the project and for public awareness complete the presentation.

\section{Vegetation dynamics within afforested coastal areas: regeneration by native species or invasion by alien species?}

Emilio Badalamenti ${ }^{1 *}$, Olimpia Campo ${ }^{2}$, Rafael Da Silveira Bueno ${ }^{1}$, Martina Gallo ${ }^{1}$, Donato Salvatore La Mela Veca ${ }^{1}$, Salvatore Pasta ${ }^{3}$, Giovanna Sala ${ }^{1} \&$ Tommaso La Mantia ${ }^{1}$

${ }^{1}$ Università degli Studi di Palermo - Dipartimento SAF, Viale delle Scienze, Palermo, Italy.

${ }^{2}$ Dipartimento Regionale dello Sviluppo Rurale e Territoriale, Viale Regione Siciliana, 4600 - 90145 Palermo, Italy.

${ }^{3}$ Université de Fribourg - Departement de Biologie, Chemin du Musée, 10, Fribourg, Switzerland.

* Corresponding author: emilio.badalamenti@unipa.it; Phone: +39-3291078849 
Keywords: Mediterranean and dune ecosystems, Acacia saligna, forest Management, Pinus pinea.

During the last century, massive reforestation projects along dunes of the southern Sicily have been carried out. Such interventions, far from being in line with current trends of close-to-nature silviculture, are, however, particularly interesting to assess vegetation dynamics in afforestation areas. Our research was conducted within "Foce del Fiume Platani" Oriented Natural Reserve, where afforestation interventions were carried out in the second half of the last century. The study area is now affected by substantial renaturalization processes, also as a consequence of the selective thinning performed in time. Such interventions aimed at reducing the density of dominant canopy species, mainly Pinus sp.pl. and Acacia saligna (Labill.) H.L. Wendl., while fostering the spread and establishment of native woody species. However, Acacia, a well recognized invader of Mediterranean-type ecosystems, started to reproduce naturally and quickly spread in the understory. The dynamics of woody vegetation within Pinus pinea $\mathrm{L}$. afforestation were evaluated by comparing results of surveys carried out in 2001 with new surveys carried out on January 2017 over three $441 \mathrm{~m}^{2}$ square plots. Acacia density has more than quintupled in just sixteen years, reaching 10,800 individuals per hectare. However, native species such as Pistacia lentiscus L. and Olea europaea var. sylvestris Mill. also displayed a notable density increase. Pistacia density increased up to 6 times, reaching a maximum density of 9,700 individuals per hectare, whereas Olea density increased as much as 800 times, with a maximum density of 120,000 individuals per hectare. Canopy cover was one of the main factors explaining the observed pattern. This study case may be emblematic for the management of afforested area in the Mediterranean where thinning aimed at favoring the renaturalization by native woody species could trigger the possible spread of invasive alien species that may counterbalance positive effects of necessary interventions.

\title{
Nuclear and chloroplast variability of Ulmus laevis populations near Belgrade (Serbia): prospects for conservation
}

\author{
Jovana Devetakovic ${ }^{1 *}$, Vladan Ivetic ${ }^{1}$, Mirjana Tihomir Šijačić-Nikolić ${ }^{1} \&$ Jelena M. Aleksic ${ }^{2}$ \\ ${ }^{1}$ University of Belgrade - Faculty of Forestry, Kneza Viseslava 1, Belgrade, Serbia. \\ ${ }^{2}$ University of Belgrade - Institute of Molecular Genetic and Genetic Engineering, Vojvode Stepe \\ 444a, Belgrade, Serbia. \\ * Corresponding author: jovana.devetakovic@sfb.bg.ac.rs
}

Keywords: Ulmus laevis, genetic variability, nuclear microsatellites, chloroplast DNA, conservation.

European white elm (Ulmus laevis Pall.) is a broadleaved deciduous tree found at riparian habitats across central and Eastern Europe. However, it is nowadays considered as a rare and endangered species in Europe because of the habitat destruction and detrimental effects of the Dutch elm disease. Its conservation is urgent, and such actions require knowledge on genetic status of remnant populations. Although European white elm populations from Europe have been studied genetically, knowledge on levels of genetic diversity and genetic structure of populations from the Balkans is still lacking. We genotyped 
93 trees from two neighboring populations of European white elm found on river islands near Belgrade, Serbia (Sava and Danube rivers) using nuclear microsatellites (nSSRs) and chloroplast DNA (cpDNA) non-coding regions. Out of the ten tested nSSRs, only two were successfully amplified. Levels of nuclear genetic diversity were high in both populations $(\mathrm{He}>0.555)$ and comparable to those observed in populations from the Iberian Peninsula and central and western Europe. Two populations, distant c. $5 \mathrm{~km}$, were not genetically differentiated (Fst $=-0.0062)$ due to the extensive gene flow $(\mathrm{Nm}=27.72$ migrants per generation). They did not experience recent bottlenecks, and their effective population sizes were 48 and three. However, contrary to previous reports on low levels of cpDNA diversity in European white elm, our preliminary results (based on the analysis of eight cpDNA regions of which four were successfully amplified in four individuals) demonstrate that variability is present in the $\operatorname{rps} 16$ - trnK region, while a duplication of a $4 \mathrm{bp}$ motif in $\operatorname{trn} \mathrm{L}$ - trnF region may be used for distinguishing diploid and triploid individuals (these considerations, however, require further analyses). In conclusion, both studied European white elm populations are good candidates for in situ conservation, and further studies of the cpDNA variability of this species may be promising.

\section{Production of European beech cultivars by grafting on different rootstocks}

Marina Zeljko Nonić* \& Mirjana Tihomir Šijačić-Nikolić

University of Belgrade - Faculty of Forestry, Kneza Viseslava 1, Belgrade, Serbia.

* Corresponding author: marina.nonic@sfb.bg.ac.rs; Phone: +38163551581

Keywords: Fagus sylvatica, European beech cultivars, grafting, nursery production, planting material.

European beech (Fagus sylvatica L.) is one of the main species in deciduous forests in Europe, which is widespread - from Sicily in Southern Italy to Bergen in Southern Norway. Along with its significance as a forest species, European beech is renowned due to its numerous cultivars, which are planted and well adapted in various green spaces. This research was performed in order to improve the production of planting material of ornamental beech cultivars, which could be grown in urban park-forests and other green spaces. Beech seedlings of different ages from natural offspring and seedlings produced in the nursery, originating from four populations in Serbia, were used as rootstocks for grafting. Three rootstocks types were used: rootstocks directly produced and planted in nursery beds, rootstocks in containers and bare root rootstocks. Scionwoods were collected from ten adult trees: three ornamental beech cultivars (Fagus sylvatica 'Purpurea', Fagus sylvatica 'Tricolor' and Fagus sylvatica 'Purpurea Tricolor') and one Moesian beech from Serbia (Belgrade area). Grafting was done in the nursery of the Faculty of Forestry, in 2011 and 2013. Two methods of copulation were applied - splice grafting and wedge grafting. After grafting performed in 2011, using rootstocks in containers, a high grafts success rate (70-80\%) was noted, but the percentage of survival at the end of the first year was lower (30-60\%). In the case of grafting on rootstocks which have been produced directly in the nursery beds, the average success of survival was $58.9 \%$ at the end of 2011 , and constantly 
kept the value of $>50 \%$ in the next three successive years. Grafting on bare root rootstocks originating from the nursery and natural offspring did not show satisfactory results, as low survival rates $(<40 \%)$ were noted. Conducted research confirms the importance of appropriate choice of grafting components, which is, along with their genetic similarity, an essential precondition for the successful production of European beech cultivars.

Online survey on forest adaptation and restoration under global change - an approach to gathering expert knowledge and local experiences worldwide

Markus Hoehl* \& Andreas Bolte

Thünen Institute of Forest Ecosystems, A.-Möller-Str. 1, 16225, Eberswalde, Germany.

* Corresponding author: markus.hoehl@thuenen.de; Phone: +49 3334 3820-364

Keywords: forest adaptation, forest restoration, best practices, online survey.

Climatic and societal changes affect forest ecosystems and confront forest managers worldwide with the challenge to increase the adaptive capacity of forests. However, sound management decisions have to be information-based, therefore the compilation of expert knowledge on local experiences with forest adaptation and restoration under global change from all parts of the world will form a profound basis for decisions on the local, regional, and international level. Both forestry practitioners and decision makers can use this information in order to develop best practice approaches that can support decision-making processes.

For this purpose, we present a novel online survey approach that gathers information on real world forest adaptation and restoration projects. This includes fundamental data on location, environmental- and forest conditions, management regimes, and actors. Furthermore, in-depth information on the targets, implementation, and success factors of the forest adaptation and restoration activities in the face of climate- and societal change will be gathered to form the basis for developing best practice approaches. The online survey is designed for multilingual use and collects standardized data that is stored in a spatial database to facilitate global application, regionalized analysis of results, and the integration with additional geodata. This survey is a core activity within the IUFRO Task Force Forest Adaptation and Restoration under Global Change and the presentation will introduce our approach to global information gathering.

We expect to motivate attendees to participate, give feedback, and learn about our research activities but also to induce new ideas for their own projects regarding the use of surveys for information gathering.

Is the use of seeds for the restoration of the Grecian juniper wood (Juniperus excelsa) stands in the Prespa National Park a good practice?

Giorgos Varsamis ${ }^{1}$, Petros Kakouros ${ }^{2 *}$, Annita Logotheti ${ }^{3} \&$ Theodora Merou $^{1}$ 
${ }^{1}$ Forestry Department, TEI EMT, 1st km Drama-Mikrohori, 66100, Drama, Greece.

${ }^{2}$ Greek Biotope/Wetland Centre, 14th km Thessalonikis-Mihanionas, PO Box 6039457001 Thermi, Thessaloniki, Greece.

${ }^{3}$ Society for the Protection of Prespa, Agios Germanos, 53077, Prespa, Greece.

* Corresponding author: petros@ekby.gr; Phone: +302310473320

Keywords: Juniperus excelsa, seeds, Prespa National Park, JunEx, old growth forests.

Greek juniper (Juniperus excelsa M. Bieb.) is distributed from Albania to Western India and from the Arabian Peninsula (Oman) to Kyrgyzstan and Ukraine. In Greece, it is located in Western Macedonia, at Nestos Gorge, in various locations of Eastern Rhodope and on the islands of Thasos, Samos and Evia. In several of these locations, it forms stands of the priority habitat type "Endemic forests with Juniperus sp." 9560. The oldest and more extensive area of this habitat type in Greece is located in Prespa National Park (PNP) at the borders with Greece, FYROM and Albania. This habitat type is gradually degrading due to the abandonment of grazing and to the dominance of highly competitive broadleaved species that suppress the Juniper trees and reduce natural regeneration. One of the restoration measures implemented in PNP, under the EU LIFE- Nature project (LIFE12 NAT/GR/539 - JunEx) was direct sowing of pre-treated seeds. The seedling survival was measured both in the laboratory and in the field. In the laboratory 5 months after germination, $15 \%$ of the seeds survived. In the field, one year after plot installation alive seedlings were found in $3 \%$ of the 5,000 plots. placed. Taking into account that a) in the 2,192 ha of the habitat type at PNP, natural regeneration has been recorded as almost absent and b) Juniperus excelsa seeds collected from PNP hold 95\% empty or damaged embryos, while only 1.75 to $5 \%$ of the embryos have been shown to be viable, the use of pre-treated seeds as a restoration measure for the Juniperus stands (Juniperus excelsa) should be considered as a good practice.

\title{
Dynamics and vulnerability of a mountain forest ecosystem: case of the cedar forest of Tikjda (Djurdjura National Park, Algeria)
}

\author{
Rachid Meddour*, Radia Larbi \& Ouahiba Meddour-Sahar \\ Université Mouloud Mammeri, Hasnaoua 2, BP 17 RP, 15000 Tizi Ouzou, Algeria. \\ * Corresponding author: rachid_meddour@yahoo.fr; Phone: +213 790159376
}

Keywords: dynamics, anthropogenic pressure, Cedrus atlantica, restoration, Algeria.

The authors aim to study the dynamics of vegetation and to estimate the intensity of anthropogenic disturbances in a mountain forest ecosystem, classified as a protected area (national park and biosphere reserve).

This study was carried out at the level of 5 forest fragments, distributed over an altitudinal amplitude of 1300 to $1800 \mathrm{~m}$, of the Tikjda cedar, located on the southern slope of Djurdjura. The floristic, ecological and structural elements of this cedar tree were analyzed by the realization of 90 floristic surveys (plots of 100 to $200 \mathrm{~m}^{2}$ ), according to the phytosociological method and a structural and dynamic approach of the stand by 
the measurement of the dbh and the height ( 40 plots of 400 to 500 square meters). Results revealed the presence of six forest species with dominance of Cedrus atlantica (average density of 230.81 trees/ha, height ranging from 2.7 to $21.7 \mathrm{~m}$ ) and Quercus rotundifolia (mean density of 55.23 individuals/ha, height from 4 to $11 \mathrm{~m}$ ). Other high woody species (Pinus nigra subsp. mauretanica, Juniperus oxycedrus, Taxus baccata, Acer obtusatum and Ilex aquifolium) have densities of 21 stems or less per hectare. On the other hand, $33 \%$ of survey sites are subjected to overgrazing of medium or high intensity, $39 \%$ to medium or high intensity woodcutting and $17 \%$ to pollution of medium or high intensity. In post-fire forest fragments, fire intensity was generally estimated to be nil or low for $88 \%$ of the plots surveyed.

These various anthropogenic disturbances on natural environments result in the massive destruction of ecosystems, in particular forests, of the national park of Djurdjura. A medium-term plan for the ecological restoration of the Tikjda forest must be undertaken in order to restore this degraded forest to its natural state.

\section{Effects of soil and plant species competition on sward restoration and plantations eight years after restoration}

Sara Martelletti ${ }^{1 *}$, Fabio Meloni ${ }^{1}$, Renzo Motta ${ }^{1}$, Michele Lonati ${ }^{1}$, Marco Pittarello ${ }^{1}$, Michele Freppaz $^{1}$, Andrea Paone ${ }^{1}$, Massimiliano Ferrarato ${ }^{2} \&$ Antonio Nosenzo $^{1}$

${ }^{1}$ University of Turin - Department of Agricultural, Forest and Food Sciences, Largo Paolo Braccini, 2 -10095 Grugliasco (TO), Italy.

${ }^{2}$ Regional Agency for Protection of the Environment - Department of Geology and Geological Instability, Via Pio VII, 9 - 10135 Turin, Italy.

* Corresponding author: sara.martelletti@unito.it; Phone: 00390116708865

Keywords: sward restoration, plantation, anthropogenic soils.

The construction and the use of infrastructures (e.g. high-speed railways) entail the loss, the fragmentation and the degradation of habitats. However, these facilities are crucial connector between countries and they will be implemented to meet human needs. As required by the current environmental regulation, environmental compensations have to be achieved to mitigate the ecological impacts. Sward restoration and plantations represent two compensation practices largely adopted, but the operation success rarely is monitored in the medium-term period.

In 2014, we assessed the effectiveness of sward restoration and plantations, eight years after their implementation, by considering pedological factors and competition among plant species. The research took place in northwestern Italy, in 32 areas set along a segment of the "Mediterranean Corridor", a high-speed railway that will link the Iberian Peninsula with the Hungarian-Ukrainian border. We collected data on herbaceous vegetation (e.g. cover of sown, non-sown, exotic and ruderal species), tree growth and soil (e.g. physical and chemical parameters). 
In general, in eight years, sward restoration was satisfying. Herbaceous cover was always higher than $60 \%$ with sown species that prevailed over non sown ones and perennial species that prevailed over annual ones. Moreover sown species limited exotic and ruderal ones $(\mathrm{p}<0.05)$. On the contrary the mean height of trees and shrubs indicate a very slow growth rate affected above all by harsh soil conditions.

Even if sward restoration was successful, these degraded areas are not completely restored, in spite of high costs of the projects. Anthropogenic soils with low organic matter content and high compaction, questionable planting techniques and lack of monitoring are among the main causes of partial failure. Therefore there is the need to look for new planting and site preparation methods, which will improve the success of restoration, and to monitor restored areas in the medium long-term period to confirm the suitability of applied techniques.

\section{Woodlands of Sicily: biodiversity, conservation and future perspectives}

Saverio Sciandrello ${ }^{1 *}$, Salvatore Brullo ${ }^{2}$, Pietro Minissale ${ }^{2}$, Carlo Prato ${ }^{1}$, Giovanni Signorello ${ }^{1}$, Giovanni Spampinato ${ }^{3} \&$ Gianpietro Giusso Del Galdo ${ }^{2}$

${ }^{1}$ Centre for the Conservation and Management of Nature and Agroecosystems (Cutgana), University of Catania, via S. Sofia 98, 95123 Catania, Italy.

${ }^{2}$ Department of Biological, Geological and Environmental Sciences, University of Catania, via A. Longo 19, 95125 Catania, Italy.

${ }^{3}$ Department of Agriculture, Mediterranean University of Reggio Calabria, Feo di Vito, 89122 Reggio Calabria, Italy.

* Corresponding author: sciandrello.s@hotmail.it

Keywords: floristic composition, ecology, fragmentation, altitudinal range.

Mediterranean woodlands are dynamic and complex ecosystems, able to provide a wide range of environmental and socio-economic benefits. Sicily is the biggest Mediterranean island and, due to its long-lasting human influence and to the high variability of environmental features, represents one of the most important center of plant diversity in the whole Mediterranean area. For millennia, Sicily has been subjected to human pressure which severely modified, fragmented and destroyed the pristine forest landscape. Sicily occupies an area of about $25,700 \mathrm{~km}^{2}$ with only $2,215 \mathrm{~km}^{2}$ ( $8 \%$ of the total regional land) covered by natural woodlands, to which $850 \mathrm{~km}^{2}$ of tree plantations have to be added. Main objectives of this research are to: 1) identify and quantify the natural wood plant communities occurring in Sicily, 2) analyze their floristic composition, ecology, chorology and conservation status, 3) defining their altitudinal range, 4) evaluate their degree of fragmentation, and lastly 5) their future perspectives, especially in terms of conservation and management of the most threatened ones.

Our study, based on literature and field surveys and supported by GIS analyses, shows: a) high diversity of woodland types represented by climatophilous plant communities (Quercetea Ilicis and Querco - Fagetea sylvaticae), edapho-xerophilous plant communities (Cisto-Lavanduletea , Junipero-Pinetea sylvestris), and edaphohygrophilous plant communities (Nerio-Tamaricetea, Salici-Populetea nigrae); b) 
which are the most important environmental factors explaining such diversity; c) how much of the Sicilian woodlands falls within N2000 network, Regional Parks or Nature Reserves; and lastly d) their fragmentation degree. Given the current woodland cover, species composition, conservation status and fragmentation, it would be desirable to implement action plans aiming at preserving the extant natural forests and, most important, at renaturalizing the artificial plantations.

\title{
Restoration practices in Mediterranean habitats using native woody species
}

\author{
Tommaso La Mantia ${ }^{1 *}$, Mario Azzarello ${ }^{1}$, Emilio Badalamenti ${ }^{1}$, Angelo Dimarca ${ }^{2}$, Domenico Fontana ${ }^{2}$, \\ Daniele Gucciardo ${ }^{2}$, Salvatore Livreri Console ${ }^{3}$, Elena Prazzi ${ }^{2}$, Salvatore Tirrito ${ }^{1} \&$ Paola Quatrini $^{1}$ \\ ${ }^{1}$ Università degli Studi di Palermo, viale delle Scienze Ed. 4, Palermo, Italy. \\ ${ }^{2}$ Legambiente Sicilia - Gestione Riserve Naturali, via Tripoli, 3, Palermo, Italy. \\ ${ }^{3}$ Area Marina Protetta "Isola di Ustica", via Petriera snc, Ustica, Italy. \\ * Corresponding author: tommaso.lamantia@unipa.it
}

Keywords: biodiversity, protected areas, management, microbial inoculation.

Since the beginning of the XXI century, Legambiente, supported by the University of Palermo, has launched several naturalization actions within Sicilian natural reserves (NR). Interventions were carried out on bare lands with the aim to restore native woody vegetation. Differently from the classical approach, consisting in the use of preparatory species usually Pines, in our approach, native shrubs and trees were used. In the NR "Isola di Lampedusa", once widely covered by woodlands and now almost desertified, a massive intervention planted 4000 plants belonging to 43 taxa (including Periploca angustifolia and Pistacia lentiscus). The combination of bioengineering techniques and the use of local genotypes led to a significant increase in vegetation cover and reduction of erosion. The NR "Lago sfondato" $(\mathrm{Cl})$ was established to preserve a peculiar karstic lake and the surrounding vegetation, hosting a number of species of conservation value, including many orchids. Interventions aiming at restoring natural woody vegetation were carried out with native species. The NR "Macalube di Aragona", a small reserve with great environmental value and high biological diversity, was intensively impacted by intensive farming and grazing. One of the main results of the interventions here was the restoration of Lygeum spartum perennial grassland, a species-rich vegetation providing notable protection against soil erosion. The re-establishment of prairies is the first step to create conditions to establish woody species. In all NR, woody plants were inoculated with symbiotic microrganisms (plant growth promoting bacteria and mycorrhizal fungi) enhancing their chance of survival and establishment after transplanting. Moreover seeds of woody legumes, were also inoculated with selected nitrogen fixing rhizobia. Such interventions suggest that the use of native species, especially local genotypes, should be the best way to restore native Mediterranean habitats, where specific propagation techniques are also recommended. 


\title{
The forest portal of Majella National Park
}

\author{
Teodoro Andrisano
}

Majella National Park Authority. Badia Morronese, Via Badia 28 - 67039 Sulmona (Aq), Italy. Email: teodoro.andrisano@parcomajella.it

Keywords: innovative information tool, forest portal, Majella National Park, WebGIS, forest restoration.

Innovation in forest restoration does not need of new technological equipment and of new methods of intervention on field.

Even an innovative information tool can effectively contribute to the work of the planners.

The forest portal of Majella National Park is an informatics tool born to support the authorization procedures management in the silvicultural field in the National Parks and it is a new tool for Italy that can support also the plan of restoration work in the protected area.

The system architecture consists of four general interdependent areas:

- authorization procedure of interventions;

- plan technical support;

- WebGIS and associated database;

- Statistics and ecosystem services secured from the forests.

The WebGIS database consists of many maps (orthophotos; topographic, geological, soil and landscape map; Regional Landscape Plan) and georeferenced layers (Digital Terrain Model, slope, exposure, inclinations, land cadastre, toponymy, road network, paths and fruition facilities, skiing, forest categories, forest types, monumental trees and forests, fires, geological constraint, the Official List Protected Areas, park zonation, SIC and ZPS, habitat Directive, grid protected species and forest parcel of management plans).

Technical support provides a single cartographic open source platform, the traditional layers, the information contained in the plans (e.g. forest parcel of management plans and also copies of forestry projects and plots), layers and naturalistic/environmental information (e.g. habitats map and grid of presence of flora and fauna protected species, for each ones predictions of the SIC and ZPS Management Plan are detailed).

The information and the data produced by the projects and the actions taken, are used by the system, after their approval, to update automatically cartographic, territorial and natural layers, and the data contained in the databases.

\section{Synchronized masting across Atlas cedar forest patches of the Djurdjura}

Nadia Abdelkrim ${ }^{1}$, Fazia Krouchi $^{1}$, Yassina Amirat ${ }^{1}$, Francois Lefevre ${ }^{2}$, Djaffer Aitsidhoum ${ }^{1}$, Federico Vessella ${ }^{3} \&$ Arezki Derridj ${ }^{1}$

${ }^{1}$ Faculty of Biological \&Agronomic Sciences, UMMTO, BP 17 RP 15000 Algeria.

${ }^{2}$ INRA, UR 629 Ecologie des Forêts Méditerranéennes, URFM Domaine Saint Paul, site AgroParc, 84914 Avignon Cedex 9 - France.

${ }^{3}$ Department of Agricultural and Forestry Science (DAFNE),Università della Tuscia, Via S. Camillo de Lellis, snc, 01100 - Viterbo, Italy. 


\author{
* Corresponding author: krfaz@yahoo.com \\ Keywords: Cedrus atlantica, synchronization, reproductive effort, cones, regeneration, Djurdjura.
}

Cedrus atlantica is a major tree species on high elevations of Saharan and Tellian Atlas in Algeria. Its regeneration relies exclusively on seeding. Therefore, periodicity and importance of reproductive events play a key role in such process. The reproductive potential of the species regarding seed production and germination capacity as well year to year variation in reproductive efforts at a local scale are documented in previous studies but synchronization in reproductive events across distant stands is less documented.

Here we investigated the reproductive output of the species across cedar forest patches of the Djurdjura mountain, including the most distant ones (Azroun'thor and Tala-guilef) over a linear distance of $36 \mathrm{kms}$, on the northern side, as well as a southern forest patch (i.e.Tikjda) at an intermediate position between the two previous ones along the mountain chain.

Cone records were made for two consecutive years (2014 and 2015) on 16 plots of $25 \times 25 \mathrm{~m}$ or $25 \times 50 \mathrm{~m}$ each. At Tikjda and Azro'nthor, only two plots were sampled per site. At Tala-guilef, 12 plots were considered across a distance of $4 \mathrm{kms}$ covering different situations of cover, slopes and elevation. Tree size parameters (total tree height and DBH, height and diameter of the crown) were associated to such records.

Results suggest a general trend consisting in a synchronized effort across stands a given year, resulting in alternatively good and low seeding years in combination with a withinstand variation explained only partially by tree size. The synchronization observed across this mountain may be driven by an extrinsic factor (i.e. climate), but inference of climatic influence on such trend may only rely on extrapolated data from neighboring sites in the absence of on-site meteorological stations. The present investigation across a single mountain could gain in accuracy through a long term survey of the same sites. It may also be extended to other ranges of Atlas cedar in Algerian for a deeper understanding of the regeneration processes and its driving factors.

\title{
Analysis of the influence of the silvicultural treatments on ecosystem services in black pine (Pinus nigra) stands in Central Italy
}

Paolo Cantiani ${ }^{1 *}$, Isabella De $\mathrm{Meo}^{2}$, Alessandra Lagomarsino ${ }^{2}$, Maurizio Marchi ${ }^{1}$ \& Alessandro Paletto $^{3}$

${ }^{1}$ CREA SEL, viale Santa Margherita 80, Arezzo, Italy.

${ }^{2}$ CREA ABP, via di Lanciola 12/A, Firenze, Italy.

${ }^{3}$ CREA MPF, Viale Nicolini 6, Villazzano (TN), Italy.

*Corresponding author: paolo.cantiani@entecra.crea.gov.it; Phone: 3478825826

Keywords: selective thinning, Pinus nigra, forest multifunctionality, Tuscany region.

Ecosystem services are considered the conditions and processes through which natural ecosystems sustain and fulfill human life. According to the Millennium Ecosystem Assessment (2005) ecosystem services can be classified in four main categories: provisioning, 
regulating, cultural, and supporting services. Concerning forests ecosystem services, their provision is influenced by site and stand characteristics and forest management practices.

The aim of the present study is to analyze the ecosystem services provided by black pine stands under different silvicultural treatments. In order to analyze the influence of silvicultural treatments on the relationships between ecosystem services, three stands located in Central Italy were chosen. These forests have been established in the sixties of twentieth century for protection purpose but not managed during the rotation period. The study areas are characterized by a similar genesis but a different current structure and future perspective. In order to enhance the multifunctionality of these forests two different silvicultural treatments (selective and traditional thinning) were applied. While the traditional thinning consists in a classical thinning from below, the selective is a localized action performed on the most promising trees per hectare, characterized by easy applicability and replicability. The innovative thinning was applied to compare its effects (economical, ecological and social) with the traditional thinning and with unmanaged areas.

Five main ecosystem services were selected and assessed: timber and bioenergy production, climate change mitigation, hydrogeological protection and biodiversity conservation. For each silvicultural treatment the biophysical assessment of selected ecosystem services was performed by using primary data and calculating one or more indicators ecosystem services. First results highlight that selective thinning enhances the majority of ecosystem services compared to the traditional thinning which has a positive influence on some components of the biodiversity.

The role of forest management practices to increase the provision of forest ecosystem services: the experiences of two LIFE projects in Central Italy

Elisa Bianchetto ${ }^{1 *}$, Paolo Cantiani ${ }^{2}$, Ugo Chiavetta ${ }^{2}$, Isabella De $\mathrm{Meo}^{1}$, Alessandra Lagomarsino ${ }^{1}$, Alessandro Paletto ${ }^{3}$, Stefano Mocali ${ }^{1}$, Silvia Landi ${ }^{1} \&$ Elena Salerni ${ }^{4}$

${ }^{1}$ Council for Agricultural Research and Economics, Research Centre for Agrobiology and Pedology (CREA-ABP), via di Lanciola, 12/a - 50125 Firenze, Italy.

${ }^{2}$ Council for Agricultural Research and Economics, Forestry Research Centre (CREA-SEL), viale Santa Margherita, 80 - 52100 Arezzo, Italy.

${ }^{3}$ Council for Agricultural Research and Economics, Research Unit for Forest Planning and Monitoring (CREA-MPF), piazza Nicolini, 6 - 38100 Trento, Italy.

${ }^{4}$ Dipartimento di Scienze della Vita - Università degli Studi di Siena, via P.A. Mattioli, 4 - 53100 Siena, Italy.

* Corresponding author: elisa.bianchetto@crea.gov.it; Phone: +39 0552492238

Keywords: black pine stand, forest management practices, thinning, Apennines, Tuscany region.

LIFE Projects SelPiBio (LIFE13 BIO/IT/000282 “Innovative silvicultural treatments to enhance soil Biodiversity in artificial black Pine stands") and FoResMit (LIFE14 CCM/IT/000905 "Recovery of degraded coniferous Forests for environmental sustainability Restoration and climate change Mitigation") are two Italian projects aimed at testing and verifying the effectiveness of forest management options on black pine stands in the Apennines 
(Italy). The main objective of silvicultural treatments realized in the frame of both projects is to increase the provision of some ecosystem services (climate change mitigation, biodiversity conservation, soil protection, bioenergy and timber production) ensuring sustainable forest management. Study areas are located in Central Italy: two in the Apennines (Pratomagno and Val d'Orcia) and the third in the hill of the Florence town (Monte Morello). Forest stands are black pine plantations established throughout the Apennines after the Second World War with the purpose of re-establishing forest cover. Black pine stands already achieved the land restoration purpose and today silvicultural treatments have the aim to enhance forest multifunctionality, trying to balance various ecosystem services. Both projects are based on testing an innovative thinning (selective thinning) which seems to be one of the most promising and interesting approach for dense artificial plantations. The thinning is a localized action performed on the most promising trees per hectare, characterized by easy applicability and replicability and known to improve the mechanical stability of trees, the growth rates and the timber production in artificial black pine plantations in the Italian Apennines chain. Furthermore, this thinning is effective in increasing soil biodiversity and improving the ecological equilibrium and climate change mitigation potential of stands. Preliminary results show that the selective thinning increases the net primary production, contains GHG emissions from deadwood decomposition, and increases bioenergy production.

\section{Protection and conservation of the manna ash landscape in Sicily}

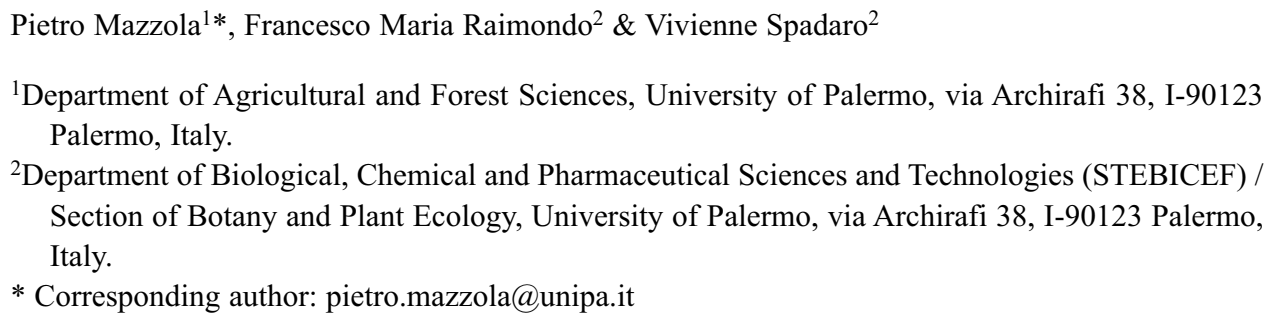

Keywords: Fraxinus, landascape management, green economy, relictual agriculture, Madonie territory.

Known as manna ashes, some local varieties of Fraxinus ornus L. and F. angustifolia Vahl (Oleaceae) are cultivated for extracting the manna, a product rich in mannose which is useful under both pharmaceutical and nutraceutical aspects. As wild plants in Sicily these ashes participate in diversifying evergreen and deciduous oak woods as well as other forest communities at the watercourse borders, together with several species of Salix, Populus and Ulmus, particularly in the hills. Cultivation of manna dates back to ancient times in Sicily and elsewhere and ash groves were increasingly spread up to the half of last century. Then, the culture had a progressive decline due to the abandonment of land and its gradual replacement by other crops. Most of the surface formerly occupied by ashes is now uncultivated and therefore also exposed to recurrent fires. As a consequence even the rich varietal heritage, documented by detailed monographs, went partially lost, although recently have not missed a revival of the local scientific community. 
In the face of the many thousands hectares occupied by these crops in the past, now residual plantations are confined in just a few hundred hectares in the territories of Castelbuono and Pollina (province of Palermo), in the northern side of the Madonie mountains. In this area the plant landscape had been strongly characterized by the ash groves, that besides acted an efficacious hydrogeological protection. At present, despite the progressive loss, the cultivation of manna ashes could still play an important role in the local economy. Therefore, in order to preserve all social, cultural and even biological values as well the landscape, it was proposed to establish a natural reserve of the manna ashes some decades ago; but that suggestion was later abandoned after the Madonie natural Park was estasblished. Nevertheless the Park has not, over the years, affected concretely the further abandonment of ash groves and the protection and conservation of the related landscape.

Recently, the Sicilian Regional government has adopted some measures aimed at supporting farmers for replanting ash groves: these are active conservation initiatives for the production of manna. Here we find it useful to propose even passive measures such as reforestation like those implemented elsewhere in the province of Palermo with good results for the environment and landscape. Other initiatives, that could not be postponed, concern vocational training as well as research and conservation of ash varieties germplasm to be grown in specific arboretums such as those already implanted in the fields of the agricultural schools at Castelbuono (Palermo) and Mussomeli (Caltanissetta) and in the experimental plantations at Sparacia (Caltanissetta), SAF Department of the Palermo University.

\section{Sustainable use of Mediterranean forest resources: the collection and recycling of cork stoppers}

Francesco Maria Raimondo*, Filippo Scafidi \& Emilio Di Gristina

Department of Biological, Chemical and Pharmaceutical Sciences and Technologies (STEBICEF) / Section of Botany and Plant Ecology, University of Palermo, via Archirafi 38, 90123, Palermo, Italy.

* Corresponding author: francesco.raimondo@unipa.it; Phone: +39091623891243

Keywords: Quercus suber, cork, botanical gardens, green economy, Mediterranean area.

Among the organic materials produced by the forest plants, in addition to the wood for the various uses, the cork is mainly used to derive the stoppers for the bottling of wines and sparkling wines. The cork oak (Quercus suber L.) is the main source of production of this material. A close connection exists between the wine growing and distribution area of this forest species. Around the world - except the Islamic and underdeveloped countries - wine and therefore also cork is consumed. The intensive use of cork is causing the decline of the cork forest and its supply for the industry. In addition, the recurring fires and the decrease of forest areas by expansion of urban centers is involving the loss of product quality. A comparable example occurring in the cork oak Maamora forest (Morocco). In the past, the efforts promoting the recycling of cork stoppers to send to the industries for the production of new cork stoppers and especially of insulating panels, have been few. Collections for these purposes have been imple- 
mented in some northern regions of Italy. Some years ago, the first author, as president of the Italian Botanical Society, exhorted the directors of the botanical gardens to organize the recycling of cork stoppers as a way of self-financing of the activities of the same botanical gardens, using their equipments and volunteers; the citizens can contribute submitting to the botanical gardens the cork stoppers collected and stored. In Italy, due to the high consumption, it would be possible to recover a considerable amount of cork for the benefit of the perpetuation of a timeless winemaking tradition and therefore also safeguarding the small cork processing industries.

\title{
Forest restoration for disaster risk reduction. Success stories in Italy
}

\author{
Riccardo Boschetto ${ }^{1}$, Carmela Cascone ${ }^{1}$, Lorenzo $_{\text {Ciccarese }}{ }^{*}$, Piera Pellegrino ${ }^{2} \&$ Valerio Silli $^{1}$ \\ ${ }^{1}$ Istituto Superiore per la Protezione e la Ricerca Ambientale, ISPRA, Roma, Italy. \\ ${ }^{2}$ Sapienza Università di Roma, piazzale Aldo Moro 4, Roma, Italy. \\ *Corresponding author: lorenzo.ciccarese@isprambiente.it
}

Keywords: disaster risk reduction, resilience, ecosystem services, sustainable local development.

The UN adopted the Sendai Framework for Disaster Risk Reduction (2015-2030) aiming to "reduction of disaster risk and losses in lives, livelihoods and health and in the economic, physical, social, cultural and environmental assets of persons, businesses, communities and countries". Among its priorities the one "Investing in disaster risk reduction for resilience" is related to ecosystem-based approach to disaster risk reduction and the enhancement of ecosystem functions.

Forest restoration, that has its major focus on restoring the relation between biodiversity and forest ecosystem functioning, may represents a key approach to mitigate risks related to natural disaster and to foster resilience of ecosystems post disasters, in natural and semi-natural habitats.

Advantages and benefits of Ecosystem-based Disaster Risk Reduction (Eco-DRR) measures include: (i) various effects becoming evident both at the time of disaster and during post-disaster rehabilitation period; (ii) effectiveness against various types of hazards; (iii) possible cost savings in initial investment and operation and maintenance using existing local natural resources; (iv) provide ecosystem services during non-disaster times; (v) involvement of local stakeholders. These advantages are emphasized by the 2030 Agenda for Sustainable Development and related sustainable development goals. In Italy, significant and replicable success stories show that Eco-DRR measures, aimed at strengthening the ecosystems' resilience and to the recovery of degraded areas, thus oriented to the biodiversity protection, are more effective and economically more affordable compared to the measures based on conventional and 'hard' structures. During the presentation we will introduce case studies of forest restoration initiatives in Italy with a DRR component. The case studies comprise establishment of short-rotation plantations on abandoned or degraded soils, tree plantings in secondary forests and other restoration projects based on controlling pressures (such as fires, invasive species, etc.) on forests. 


\title{
Sentinel-2 imagery for mapping Cork oak (Quercus suber) distribution in Calabria (Italy): capabilities and quantitative estimation for forest restoration activities
}

\author{
Giuseppe Modica*, Angelo Merlino \& Francesco Solano
}

Agriculture Department "Mediterranea" University of Reggio Calabria, 89122 Reggio Calabria (Italy).

*Corresponding author: giuseppe.modica@unirc.it

Keywords: Sentinel-2 (S-2), Landsat 8 OLI, Spectral signature, cork oak woodlands, Calabria (Italy), Red-edge position (REP).

The objectives of this research refers to the potential in using new Sentinel-2 (S-2) remote sensing imagery and in situ surveying for mapping and monitoring Cork oak (Quercus suber L.) woodlands in Calabria region, for restoration purposes. Considering that S-2 spectral bands are particularly suitable for estimating different vegetation cover characteristics, we propose a methodology for mapping the actual consistence of this habitat, using the Red-edge position (REP) in the vegetation spectral reflectance to evaluate cork oak spectral response and classify this vegetation type. A set of different S-2 and L8 OLI scenes where freely downloaded and pre-processed (topographic and atmospheric correction, band anomaly detection) in order to better investigate cork oak spectral signature. The selected sensor bands where used to perform spectral signature separability and the results where compared. Normalized Difference Red Edge Vegetation Index (NDRE) and Normalized Difference Vegetation Index (NDVI) where calculated to obtain a high spectral resolution vegetation mask. Then a Digital Elevation Model (DEM) was used as threshold of altitude ecological limit to clip the vegetation mask where to run the classification. Signature training sets, GCP and ancillary data where used to perform a supervised classification of both S-2 and L8 OLI imagery. Furthermore an accuracy assessment was applied to the classified images in order to evaluate the user's and the producer's accuracy. S-2 provides a great opportunity for global vegetation monitoring due to its enhanced spatial, spectral and temporal characteristics compared with Landsat. Results confirm the importance of the red-edge bands on Sentinel-2 for vegetation applications, because of the combination with its high spatial resolution of $20 \mathrm{~m}$ and the possibility to use peculiar vegetation indices to analyze vegetation behaviour. The performed images classification of cork oak distribution suggested that, when these images integrate with other ancillary data, it becomes possible to map species as well as to carry out other studies at regional scale with a high overall accuracy. Derived vegetation indices proved to be an accurate tools in detecting and monitoring cork oak woodlands health for restoration activities.

\section{Main types of forest, macchia and garigues of Sardinian island}

Ignazio Camarda*, Antonello Brunu, Luisa Carta, Gabriella Vacca \& Giuseppe Brundu

Department of AGRARIA, University of Sassari, Viale Italia 3907100 Sassari-Italy.

*Corresponding author: icamarda@hotmail.it 
Keywords: forest, macchia, garigues, Sardinia.

The evergreen sclerophyllous vegetation represents the main forest type of Sardinia. Floristic composition, physiognomy and structure are extremenly variable, depending both on geology, climate and human impacts since ages. Main types of vegetation and the dominant species in forest, macchia and garigues are taken into account in relation to the processes of degradation. More than two hundred physiognomic types of vegetation are included in the 5 phyto-climates given for Sardinia.

The evergreen forest vegetation are dominant with Quercus ilex L., Olea europaea var. sylvestris (Mill.) Brot., Ceratonia siliqua L., Ilex aquifolium L., the coniferous trees of the genus Pinus (Pinus pinea L., P. halepensis Mill., P. pinaster Ait., Juniperus (J. phoenicea L., J. oxycedrus L., J. oxycedrus subsp. macrocarpa (Sm.) Ball, J. communis L.) and Taxus baccata L. A particular condition is given by the forests of Quercus suber L., whose origin is typically anthropic. Among the species of the deciduous species, oaks forests (Quercus pubescens Willd., s. 1.) are frequent from hilly areas to the limit of $1500 \mathrm{~m}$, while rare forests are formes by Ostrya carpinifolia (L.) Scop, Acer monspessulanum L. and Fraxinus ornus L. Shrubs as Phillyrea latifolia L., Arbutus unedo L., Pistacia lentiscus L. P. terebinthus L., Quercus coccifera L., Laurus nobilis L., Myrtus communis L., Rhamnus alaternus L., Erica arborea L., Erica scoparia L., Phillyrea angustifolia L., Cytisus villosus (L.) Pourret, Chamaerops humilis L., Juniperus sibirica Burgsd. and decidous thermophylous species as Calycotome villosa L., Anagyris foetida L., Euphorbia arborea L. are the fundamental elements of the macchia. The degradation of the macchia leads to garigues, where small shrubs (Teucrium marum L., Helichrysum italicum subsp. microphyllum (Willd.) Nyman, Euphorbia spinosa L., Genista sp. pl., Cistus sp.pl., Lavandula stoechas L., Santolina sp. pl. and Rosmarinus officinalis L. ) are prevalent. These species are provided with aromatic substances, toxic or thorny as a defense from excessive insolation, aridity and by grazing animals. The garigues widespread above all in coastal and highmountain areas, generally represent a degradation stage of the Mediterranean shrubs and woodlands.

The evergreen vegetation of the rivers is mainly represented by the formations of Nerium oleander L. and Tamarix africana Poir., while the hygrophilous forests of Alnus glutinosa (L.) Gaertner, Populus alba L., Ulmus minor Mill., Fraxinus oxycarpa Willd. and Salix sp. p.l, are common from sea level up to $1600 \mathrm{~m}$ above the sea level. The forest vegetation for productive purposes are limited to Castanea sativa Mill. and Corylus avellana L., while the reforestation measures in the island started in the last decades with conifers, either spontaneous ( . pinaster, P. halepensis and P. pinea) and exotic as the Pinus nigra Arnold, P. brutia Ten, $P$. canariensis Sprengel, Abies alba Mill., and in recent times Pinus radiata D. Don, Abies cephalonica Loudon, A. nordmanniana (Steven) Spach, Cedrus atlantica (Endl.) Carrière, Cupressus sempervirens L., C. arizonica A.L. Greene, C. macrocarpa Hartweg. Among the decidous species the most commonly used in reforestation are Eucalyptus camaldulensis Dehnh. and Acacia cyanophylla Lindley s. 1. which now represent a significant part of the island landscape. 
Environment, human impact and the role of trees on the Po plain during the Middle and Recent Bronze Age: Pollen evidence from the Terramara of Santa Rosa di Poviglio (SUCCESSO-TERRA)

Anna Maria Mercuri*, Assunta Florenzano \& Paola Torri

Laboratorio di Palinologia e Paleobotanica, Dipartimento di Scienze della Vita, Università di Modena e Reggio Emilia.

*Corresponding author: annamaria.mercuri@unimore.it

Keywords: palynology, cultural landscape, Bronze Age, wood management, Po plain.

The national-funded project SUCCESSO-TERRA (Human societies, climate-environment changes and resource exploitation/sustainability in the Po Plain at the Mid-Holocene times: the Terramara) focuses on an interdisciplinary geoarchaeological and archaeobotanical investigation on the Terramare Middle Bronze Age culture, which developed in the central-southern Po Plain from around 1550 to around 1170 years BC (Cremaschi et al. 2016, Climate change versus land management in the Po Plain (Northern Italy) during the Bronze Age: new insight from the VP/VG sequence of the Terramara Santa Rosa di Poviglio. Quat. Sci. Rev. 136: 153-172). The land transformations that occurred at the onset, duration, and end of the Terramare culture has been investigate through the study of several terramare villages $(\mathrm{T})$ and necropolis $(\mathrm{N})$ including $\mathrm{T}$ Montale, T Baggiovara, N Casinalbo, T Santa Rosa di Poviglio. The Terramare wew banked and moated villages that developed in the central sector of Po River alluvial plain during the Middle and Late Holocene. The relationships between the Late Holocene regional environmental and landuse changes have been investigated to obtain a detailed comprehension of adaptive strategies of the Terramare people during the Middle/Recent Bronze ages. The palynological research demonstrated that the wood had a key role in the development of this cultures characterized by a sophisticated dynamic agricultural economy. The latter was expressly practiced on the basis of wood management and cereal/legume fields. At the top of the sequence of Santa Rosa di Poviglio, in correspondence with the drying of the moat system, a dramatic decrease of woods may had a twofold causation: increased aridity (natural factor) and intensive land-use (anthropic factor) might have played a fairly synchronous action on vegetation. 


\section{Index of authors}

\begin{tabular}{|c|c|}
\hline Abdelkrim N. ...... & Campisi P. \\
\hline Acebal A. ............. & Campo O. . \\
\hline cevedo M. .......................... & Cancellieri F. \\
\hline dutwumwaa Derkyi M. F. . & Cano E. .......... \\
\hline 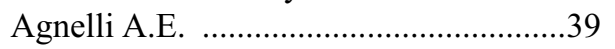 & Cano Ortiz A. ............... \\
\hline 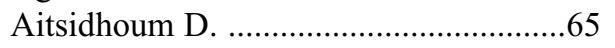 & Cantiani P. ...................... \\
\hline ledo A. ............... & Carella R. ........ \\
\hline leksic J.M. ........ & Tarta L. ........... \\
\hline llegrini A. .......... & Cartes E. .......... \\
\hline mirat Y. .............. & Casamento G. . \\
\hline ndrisano T. ....... & Cascone C. ..... \\
\hline ngelini A. .......... & Chaudron A. ... \\
\hline ronne G. ........... & Cherubini P. .. \\
\hline zzarello M. ....... & Chiatante D. .. \\
\hline adalamenti E. ... & Chiavetta U. ....... \\
\hline aliva M. ........... & Chirici G. ........... \\
\hline no A. .......... & g W. ....... \\
\hline$\ldots \ldots . .14$ & io O. ....... \\
\hline$\ldots .24,28$ & chetti G. ... \\
\hline .........22 & Ciccarello S. ... \\
\hline elletti P. ....... & Ciccarese L. ... \\
\hline enedetti S. ......... & Collet C. ....................... \\
\hline ........43 & na $J . . . . . . . .$. \\
\hline etto E. ....... &. .14 \\
\hline ........49 & Čufar K. ........... \\
\hline t M. ....... & Da Silveira Bue \\
\hline .....6, 60 & Dato G. ..... \\
\hline .........16 & $. .34,39,66,67$ \\
\hline .........70 & $\ldots \ldots \ldots .24,28$ \\
\hline ..........12 & o G. ....... \\
\hline ..........46 & .............54 \\
\hline ..........23 & $\ldots 18,21,23,65$ \\
\hline ..........43 & $\ldots 25,58$ \\
\hline ...........14 & $\ldots .26,53$ \\
\hline ............63 & ..........69 \\
\hline .............71 & $\ldots 10,20$ \\
\hline ...........71 & $\ldots .55,64$ \\
\hline ...........13 & a A. ............ \\
\hline ...........11 & Domina G. ................ \\
\hline ............71 & lianou F. .......... \\
\hline ….........34 & Ducci F. ......................... \\
\hline .........25, 44 & \\
\hline ..............14 & Fabiano F. ....... \\
\hline Camillotti G. & Facciotto G. .... \\
\hline
\end{tabular}


Fennane M. . .43

Fernandez C.

Loewe V. .7

Fernández-García V.

Logotheti A. ...................................37, 60

Fernández-Guisuraga J.M.

Lonati $\mathrm{M}$.

Ferrarato M.

Lopez G. .16

Filibeck G. .......................................26

Florenzano A. ...................................... 73

Fontana D. ............................................64

Freppaz M. ..........................................62

Galetti M. .............................................47

Gallo M. ...............................................57

Garcia D. .............................................47

Gargano M.L. ................................20, 29

Gavinet J. .............................................. 8

Giannetti F. ............................................44

Giaramida G. ........................................55

Giusso Del Galdo G. ............................63

Gonzalez M. ............................................

Greco R. .......................................50

Gucciardo D. ........................................64

Guechoud I. ...........................................21

Guerrini S. ........................................... 36

Hansen O.K. ..........................................41

Hajny M. T. ..........................................15

Heinrich I. ..........................................53

Hidalgo P.H. ............................................51

Hoehl M. ...............................................60

Isajev V. ......................................19, 56

Ivetic V. ......................................25, 58

Jokanovic D.D. .....................................48

Kakouros P. .............................................60

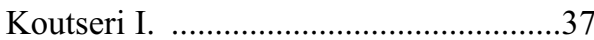

Krouchi F. ..........................18, 21, 23, 65

López-Tirado J. ...............................27, 51

Lovero M. ...............................................46

Lucic A. ..............................................56

Madsen P. ........................................6, 41

Maetzke F.G. .........................................19

Maltoni A. ...............................................25

Mammadova A. .......................................35

Marani M. ............................................ 30

Marchetti M. ........................................10

Marchi E. ...........................22, 25, 44, 66

Marcos E. .................................................11

Mariotti B. ...........................................25

Marras T. ...........................................33

Martelletti S. ........................................62

Marzulli M.I. ...........................................50

Mataruga M. .........................................56

Mazza G. .........................................34, 39

Mazzola P. .............................................68

Meddour R. ............................................61

Meddour-Sahar O. .................................61

Meloni F. ..........................................43, 62

Mensing S. ..........................................26

Mercuri A.M. .........................................73

Mercurio R. ............................................. 7

Merlino A. ............................................. 71

Merou T. .................................................60

Minissale P. ..................................52, 63

Mocali A. ................................................67

Modica G. ................................................71

Montagnoli A. .........................................29

Monteverdi M.C. ...................................13

Moretti N. .............................................38

Motta R. ........................................43, 62

Moukrim S. ..........................................51

Musarella C.M. ...............................14, 54

Naggar M. ............................................51

Nikolic V.M. .........................................48

Nocentini L. .............................................15

Nosenzo A. ....................................43, 62

Notarangelo M. ......................................38

Orfanoudakis M. ..................................39

Ortiz G. ........................................16, 52

Ljubinko R. .........................................56

Lo Paro G. ................................................56 
Ortolani M.R. ..........................................30

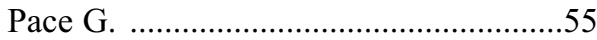

Paletto A. ...............................34, 66, 67

Palla F. .................................................. 17

Paone A. ...........................................62

Pasta S. ....................................................57

Pellegrino P. ...................................... 70

Persia M. .................................................50

Pettenella D. ...................................36, 42

Piccione V. .........................................56

Pignatti G. ..........................................40

Piñar Fuentes J.C. .............................54

Pinto Gomes C.J. ....................................54

Piovesan G. ...................................26, 53

Pittarello M. ..........................................62

Pleiss V. ................................................46

Poduška Z. .............................................19

Prato C. .................................................63

Prazzi E. .........................................64

Prévosto B. ............................................ 8

Privitera M. ............................................10

Proietti R. ...............................................13

Puglisi M. ................................................. 10

Quatrini P. ..........................................64

Quilghini G. ........................................12

Quiroz I. ..................................................

Radoglou K. ...........................14, 31, 39

Ragno D. .............................................. 33

Raimondo F.M. 9, 17, 20, 35, 43, 48, 56, 68, 69

Rakonjac L. ..........................................19

Regato Pajares P. .................................46

Rejdali M. ..............................................44

Richter C. ..............................................45

Rojas-Briales E. .....................................36

Roumeliotou V. ...................................37

Sagheb-Talebi K. .................................41

Sakai H. ................................................ 32

Sakurai R. ...............................................32

Sala G. .............................................. $57 \mathrm{~s}$

Salmeri C. ...............................................48

Salerni E. ................................................67

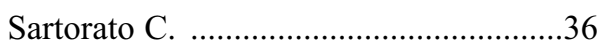

Scafidi F. ..............................................6 69

Schettino A. .............................................53

Schirone A. ..............................................30
Schirone B. ............................23, 27, 33

Scialabba A. ............................................17

Sciandrello S. ...............................52, 63

Scippa G.S. ........................................29

Scuto S. ..................................................56

Sferlazza S. ...........................................19

Šijačić-Nikolić M.T. ........................58, 59

Signorello G. ...........................................63

Silli V. ............................................... 70

Solano F. .................................................. 71

Spada F. .........................................32, 45

Spadaro V. ..............................................68

Spampinato G. ...................10, 14, 54, 63

Sperandio G. ...........................................40

Stankovic D. ......................................48

Stanturf J.A. .....................................6, 38

Suárez-Seoane S. ....................................11

Tani A. .....................................................25

Tarantino C. ..............................................50

Tartarino P. ...............................................49

Terzaghi M. .........................................29

Terzuolo P.G. .............................................44

Tirrito S. .................................................64

Tomaselli V. ..........................................49

Torri P. .................................................... 73

Travaglini D. .........................................44

Tunno I. .............................................26

Ulrich E. .................................................45

Vacca G. ................................................. 71

Vacchiano G. ...........................................43

Vadevenito G. .......................................... 7

Varsamis G. ............................................60

Verani S. ...................................................40

Veronico G. ...............................................49

Vessella F. ..................21, 23, 27, 51, 65

Venturella G. ...................................20, 29

Vilotic D.M. ............................................48

Wellstein C. ....................................32, 33

Yildiz O. .................................................17

Yoshida M. ...............................................32

Zalloni E. .................................................23

Zeljko Nonić M. .....................................59

Zocchi A. ...............................................22 